\title{
Lung epithelial cell lines in coculture with human pulmonary microvascular endothelial cells: development of an alveolo-capillary barrier in vitro
}

\author{
Maria Iris Hermanns ${ }^{1}$, Ronald E Unger ${ }^{1}$, Kai Kehe ${ }^{2}$, Kirsten Peters ${ }^{1}$ and \\ Charles James Kirkpatrick ${ }^{1}$ \\ ${ }^{1}$ Institute of Pathology, Johannes Gutenberg-University, Mainz, Germany and ${ }^{2}$ Bundeswehr Institute of \\ Pharmacology and Toxicology, Munich, Germany
}

\begin{abstract}
We have established a coculture system of human distal lung epithelial cells and human microvascular endothelial cells in order to study the cellular interactions of epithelium and endothelium at the alveolocapillary barrier in both pathogenesis and recovery from acute lung injury. The aim was to determine conditions for the development of functional cellular junctions and the formation of a tight epithelial barrier similar to that observed in vivo. The in vitro coculture system consisted of monolayers of human lung epithelial cell lines (A549 or $\mathrm{NCl} \mathrm{H441)} \mathrm{and} \mathrm{primary} \mathrm{human} \mathrm{pulmonary} \mathrm{microvascular} \mathrm{endothelial} \mathrm{cells} \mathrm{(HPMEC)} \mathrm{on} \mathrm{opposite} \mathrm{sides}$ of a permeable filter membrane. A549 failed to show sufficient differentiation with respect to formation of a tight epithelial barrier with intact cell-cell junctions. Stimulated with dexamethasone, the cocultures of $\mathrm{NCl} \mathrm{H} 441$ and HPMEC established contact-inhibited differentiated monolayers, with $\mathrm{NCl}$ H441 showing a continuous, circumferential immunostaining of the tight junctional protein, ZO-1 and the adherens junction protein, E-cadherin. The generation of a polarized epithelial cell monolayer with typical junctional structures was confirmed by transmission electron microscopy. Dexamethasone treatment resulted in average transbilayer electrical resistance (TER) values of $500 \Omega \mathrm{cm}^{2}$ after 10-12 days of cocultivation and correlated with a reduced flux of the hydrophilic permeability marker, sodium-fluorescein. In addition, basolateral distribution of the proinflammatory cytokine tumour necrosis factor-alpha caused a significant reduction of TER-values after $24 \mathrm{~h}$ exposure. This decrease in TER could be re-established to control level by removal of the cytokine within $24 \mathrm{~h}$. Thus, the coculture system of the NCI H441 with HPMEC should be a suitable in vitro model system to examine epithelial and endothelial interactions in the pathogenesis of acute lung injury, infectious lung diseases and toxic lung injury. In addition, it could be used to improve techniques of lung drug delivery that also requires a functional barrier.
\end{abstract}

Laboratory Investigation (2004) 84, 736-752, advance online publication, 12 April 2004; doi:10.1038/labinvest.3700081

Keywords: alveoli; type II pneumocyte; microvascular endothelium; coculture; HTS 24-Transwell; adherens junctions; tight junctions; bilayer

A key role of epithelia and endothelia is the formation of diffusion barriers that allow the generation and maintenance of compartments with different compositions, a fundamental requirement for the physiological functioning of organs. ${ }^{1}$ One of the vital barriers in the human body is the blood-air

Correspondence: Professor Dr CJ Kirkpatrick, Institute of Pathology, Johannes Gutenberg University, Langenbeckstrasse 1, D-55101 Mainz, Germany.

E-mail: kirkpatrick@pathologie.klinik.uni-mainz.de

This paper is dedicated to Professor Dr. L. Szinicz on his retirement from the Institute of Pharmacology and Toxicology at the FAF Medical Academy in Munich.

Received 23 July 2003; revised 23 December 2003; accepted 27 December 2003; published online 12 April 2004 interface in the lung. With an area of approximately $100-140 \mathrm{~m}^{2,2}$ the alveoli of the human lung are functionally the most important element of the lung.

Owing to the complexity of the alveolar system, little is known about the interactions between microcirculation and epithelium within the alveolar space. Most investigators have concentrated their efforts on studying lung endothelial injury when examining pathological conditions. Increasingly, the alveolar epithelial barrier has been shown to play a central role in pulmonary disease. ${ }^{3}$ Various morphological and physiological studies demonstrated that the alveolar barrier offers a much greater resistance to the movement of solutes and protein than the nearby endothelium. ${ }^{4-6}$ 
The alveolar epithelium consists of two specialized epithelial cell types. The terminally differentiated squamous alveolar epithelial type I (ATI) cell that constitutes approximately $93 \%$ of the alveolar surface area and the surfactant producing cuboidal alveolar epithelial type II (ATII) cell. While the ATII cell only covers $7 \%$ of the alveolar surface area it constitutes $67 \%$ of the epithelial cell number within the alveoli ${ }^{7}$ pointing to its biochemical importance. The major functions attributed to ATII cells are the synthesis of surfactant, the transepithelial movement of water and ions, the metabolism of xenobiotics and the regeneration of alveolar epithelium following lung injury. ${ }^{8-14}$ The surfactant film not only has a regulatory function to lower the surface tension in lungs but is also involved in innate immune responses in the lung via the ability of surfactant protein-A (SP-A) and SP-D to bind various pathogens including viruses, bacteria, fungi and particulates such as pollen grains and mite allergens. ${ }^{15}$

To generate a functional barrier in vitro, one main precondition is the establishment of tight junctions (TJ) and adherens junctions (AJ) between adjacent cells. TJ are located at the most apical region of lateral membranes of epithelial cells and are thought to function as a fence between apical and basolateral plasma membrane domains to create and maintain their polarity. ${ }^{16} \mathrm{ZO}-1$ is one of the major cytoplasmatic proteins of the TJ and has been found to be associated with the transmembrane protein occludin and to link it to the actin-based cytoskeleton. ${ }^{17}$ The formation of the TJ is accompanied by $\mathrm{AJ}$ and these two distinct junctions show not only an intimate spatial but also a functional relationship. ${ }^{18-20}$ In contrast to the epithelium, endothelium does not show a clear morphologic differentiation into AJ and apical TJ, with both junctional structures present along the complete lateral aspect of the endothelial contacting zones. ${ }^{21,22}$ AJ contribute to the maintenance and regulation of the cellular barrier by forming homotypic bonds with adjacent cells via $\mathrm{Ca}^{2+}$-dependent interactions. The integral membrane component of AJ is E-cadherin or VEcadherin (cadherin-5), for epithelial or vascular endothelial cells, respectively, which interacts with the actin cytoskeleton via cytoplasmatic proteins, the $\alpha$-, $\beta$ - and $\gamma$-catenins. ${ }^{23-25}$

As TJ are highly dynamic structures capable of rapid alterations in disease and in response to functional stress ${ }^{26}$ their assembly in vitro is dependent upon the differentiation of cells. In previous studies, existing human distal lung epithelial cell lines failed to develop substantial transepithelial resistance (TER) indicating the lack of TJ-mediated epithelial barrier formation ${ }^{27-29}$ or insufficient differentiation. Proliferation and differentiation of cells is known to be highly dependent upon the choice of culture conditions, such as treatment with growth factors and hormones as well as cocultivation with adjacent cell types. Several in vitro models have shown that glucocorticoids tighten cellular contacts in mammary epithelium, retinal endothelium and brain microvascular epithelium..$^{30-33}$ On the other hand, proinflammatory cytokines, like tumour necrosis factor-alpha (TNF- $\alpha$ ), act in a contrary fashion, influencing intercellular interactions and permeability across epithelial and endothelial cells. In lung pathobiology, TNF- $\alpha$ is a mediator of sepsis syndrome and the acute respiratory distress syndrome. ${ }^{34-37}$ TNF- $\alpha$ induces an increase in pulmonary vascular permeability in $v_{i v o,}{ }^{38}$ in the isolated lung, ${ }^{39,40}$ and in pulmonary arterial and microvessel endothelial monolayers. ${ }^{41-43}$

To simulate a functional lung-blood barrier, we investigated a coculture system of human distal lung epithelial cell lines (A549 and NCI H441) and primary human pulmonary microvascular endothelial cells (HPMEC). The cells were allowed to reach confluence, differentiated into their respective phenotypes and were examined for the establishment of cell-cell junctions and the formation of a tight epithelial barrier. These parameters were also studied in the presence of the glucocorticoid dexamethasone (Dex) in monocultures of human lung epithelial cell lines and cocultures of human lung epithelial cell lines and primary microvascular endothelial cells. Furthermore, the influence of TNF- $\alpha$ exposure on the established coculture was examined with TNF- $\alpha$ acting as a model proinflammatory cytokine in acute lung disease.

\section{Materials and methods}

\section{Cells and Cell Culture}

Human adult pulmonary microvascular endothelial cells (EC) were obtained from macro- and microscopically normal portions of lung specimens surgically resected from patients who underwent lobectomies for early stage lung cancer. The present study was approved by the ethics committee of the University of Mainz and informed consent as defined by the Helinski Declaration was obtained from each patient. HPMEC were isolated from lung specimens as previously described. ${ }^{44}$ Briefly, the lung specimens were digested by dispase and elastase treatment and the cells were cultured in HPMEC medium (MCDB $131+15 \%$ foetal calf serum (FCS) + $2 \mathrm{mM}$ glutamax + penicillin/streptomycin (Pen/Strep) $\quad(100 \mathrm{U} / 100 \mu \mathrm{g} / \mathrm{ml})+$ heparin $(10 \mu \mathrm{g} / \mathrm{ml})+$ bFGF $(2.5 \mu \mathrm{g} / \mathrm{ml}$; Sigma, Taufkirchen, Germany)) in tissue culture flasks coated with gelatin $(0.2 \%)$ for several days until subconfluent. Endothelial cells expressing platelet endothelial cell adhesion molecule (PECAM-1, CD31) were isolated using the Dynabeads CD31 Endothelial Cell kit (Dynal, Oslo, Norway) according to the instructions of the manufacturer. Fresh medium was added every 2-3 days, and the cells were subcultured 1:3 with trypsin/EDTA treatment of confluent monolayers. More than $99 \%$ of the cells were shown to be endothelial cells by staining for CD31 and vWF. 
The human lung adenocarcinoma cell lines, A549 (ATCC-CCL-185) and NCI H441 (ATCC-HTB-174), were obtained from ATCC (Promochem, Wesel, Germany). The A549 cells were propagated in HPMEC medium with 5\% FCS, the NCI H441 cells were cultured in RPMI 1640 medium with L-glutamine supplemented with 10\% FCS and Pen/Strep (100 U/100 $\mu \mathrm{g} / \mathrm{ml})$ at $37^{\circ} \mathrm{C}, 5 \% \mathrm{CO}_{2}$. The serum substitute ITS $^{+}$(insulin, transferrin, selenious acid, linoleic acid, BSA) was from BD Labware (Heidelberg, Germany). MCDB 131, RPMI, FCS, glutamax and Pen/Strep were purchased from Life Technologies (Karlsruhe, Germany).

\section{Coculture of HPMEC with A549 or NCI H441}

HPMEC $\left(5 \times 10^{4} / \mathrm{cm}^{2}\right)$ were placed on the lower surface of an inverted collagen type I from calf skin (IBFB, Leipzig, Germany)-coated HTS 24-Transwell ${ }^{\circledR}$ filter (polycarbonate, $0.4 \mu \mathrm{m}$ pore size; Costar, Wiesbaden, Germany) membrane and incubated for $2 \mathrm{~h}$ at $37^{\circ} \mathrm{C}$ and $5 \% \mathrm{CO}_{2}$. The filter plates were then inverted and placed in 24-well plates filled with $1 \mathrm{ml}$ HPMEC medium (5\% FCS) per well. A549 or NCI H441 $\left(2 \times 10^{4} / \mathrm{cm}^{2}\right)$ cells were subsequently seeded on the top surface of the HTS 24-Transwell ${ }^{\mathbb{R}}$ filter membranes $(190 \mu \mathrm{l} /$ well) and grown to confluence simultaneously with the HPMEC on the lower surface over 10-14 days, using the same conditions outlined for flasks. Cocultures and mono-cultures as controls were allowed to reach confluence for 3 days after which fresh medium was replaced every second day for further experiments. For the Dextreated cells, $190 \mu \mathrm{l}$ of fresh medium supplemented with $1 \mu \mathrm{M}$ Dex (Sigma, Taufkirchen, Germany) was added to the apical well beginning at day 3 .

\section{Antibodies}

Anti-rabbit SP-A, -B, -C, -D were obtained from Santa-Cruz Biotechnologies (Heidelberg, Germany). Mouse monoclonal anti-E-cadherin (uvomorulin, L-CAM) was obtained from Monosan (CellSystems, St Katharinen, Germany) anti-TTF-1 from NeoMarkers (Dunn, Asbach, Germany). Rabbit polyclonal anti-ZO-1 antibody was purchased from Zymed Laboratories Inc. (South San Francisco, CA, USA). Mouse monoclonal anti-human cadherin-5 (VE-cadherin) was from BD Transduction Laboratories (Heidelberg, Germany). The secondary antibodies, Alexa fluor 488-conjugated anti-mouse IgG and Alexa fluor 594conjugated anti-rabbit IgG, were from Molecular Probes (MoBiTec, Göttingen, Germany).

\section{Immunocytochemical Staining}

For characterization studies the cells were grown to confluence on collagen coated $\left(14.5 \mu \mathrm{g} / \mathrm{cm}^{2}\right)$. eightwell chamber slides. All other studies were carried out by growing the cells in mono- and coculture on permeable filter supports. At various times of cultivation (see single experiments), the cells were washed in phosphate-buffered saline (PBS) with calcium, fixed with paraformaldehyde $(3.7 \%)$ in CS buffer piperazine- $N, N^{\prime}$-bis (2-ethanesulfonic acid) (PIPES) $0.1 \mathrm{M}$, ethyleneglycol-bis ( $\beta$-aminoethylether) $N, N, N^{\prime}, N^{\prime}$-tetraacetic acid (EGTA) $1 \mathrm{mM}, 4 \%$ polyethylene glycol $800, \mathrm{NaOH} 0.1 \mathrm{M}$ ) for $20 \mathrm{~min}$, and washed twice in PBS. The filter membranes were further permeabilized with $0.5 \%$ Triton X-100 in PBS and the respective primary antibodies (in PBS $+3 \%$ bovine serum albumin (BSA)) were added and incubated overnight at $4^{\circ} \mathrm{C}$. Cells were washed four times in PBS and incubated with a fluorochrome-coupled secondary antibody for $3 \mathrm{~h}$. For the single staining experiments, the secondary antibody was conjugated with Alexa fluor-488. In case of double staining, the first antibodies were from different species, for example, rabbit and mouse; here the second antibody against mouse was conjugated with Alexa fluor-488 (green fluorescence) and the anti-rabbit antibody with Alexa fluor-594 (red fluorescence). The nuclei were counterstained with a blue fluorescent Hoechst dye (HOE 33342, Sigma, Germany). Three washes were carried out in PBS/0.1\% Triton X-100. The filter was punched out from the plastic support and mounted on a slide in Gel/Mount (Biozol, Eching, Germany). The specimens on both sides of the permeable filter support were observed by fluorescent microscopy (Leitz DMRX, Leica, Germany).

\section{Bioelectrical Measurements}

The transmonolayer and transbilayer electrical resistance was expressed in $\Omega \mathrm{cm}^{2}$ and measured using an EVOM voltohmmeter (World Precision Instruments, Berlin, Germany) equipped with a pair of STX-2 chopstick electrodes. Briefly, HTS 24Transwell ${ }^{\mathbb{R}}$ filter membranes without cells, filter membranes with cells in the culture medium, and filter membranes with cell lines in medium supplemented with $1 \mu \mathrm{M}$ Dex on day 3 of cocultivation were examined over a cultivation period of 10-14 days. Electrodes were placed at the upper and lower chambers and resistance measured with the voltohmmeter. Resistance was shown as the mean resistance*area of three independent experiments. Calculations for $\Omega \mathrm{cm}^{2}$ were made by subtracting the resistance measurement of the blank filter coated with collagen type I (approximately $110 \Omega$ ) and multiplying by the area of the monolayer $\left(0.33 \mathrm{~cm}^{2}\right)$.

\section{Transport Study}

Monocultures of NCI H441 and cocultures of NCI H441 and HPMEC on day 11 in culture were used in the transport study. The paracellular flux of sodiumfluorescein with a molecular weight of $376.3 \mathrm{Da}$ at $37^{\circ} \mathrm{C}$ was measured across the mono- and bilayers in an apical-to-basolateral direction. Following $2 \mathrm{~h}$ equilibration in bicarbonated Krebs-Ringer-buffer 
(KRB; $1.1 \mathrm{mM} \mathrm{MgCl}_{2} * 6 \mathrm{H}_{2} \mathrm{O}, 1.25 \mathrm{mM} \mathrm{CaCl}_{2} * 2 \mathrm{H}_{2} \mathrm{O}$, $114 \mathrm{mM} \mathrm{NaCl}, 5 \mathrm{mM} \mathrm{KCl}, 1.65 \mathrm{mM} \mathrm{Na}_{2} \mathrm{HPO}_{4} * 7 \mathrm{H}_{2} \mathrm{O}$, $0.3 \mathrm{mM} \quad \mathrm{NaH}_{2} \mathrm{PO}_{4} * 2 \mathrm{H}_{2} \mathrm{O}, 10 \mathrm{mM}$ HEPES, $20 \mathrm{mM}$ $\mathrm{NaHCO}_{3}$, and $25 \mathrm{mM}$ glucose, $\mathrm{pH}$ 7.4), transport experiments were started by replacing the apical fluid $(190 \mu \mathrm{l})$ with sodium-fluorescein (Acid Yellow 73; Sigma, Taufkirchen, Germany) in a concentration of $10 \mu \mathrm{g} / \mathrm{ml}$ in KRB. Samples from the acceptor fluid in the lower well (basolateral) were taken every 20 min over a time period of $3 \mathrm{~h}$, replaced with an equal volume of fresh KRB. The samples were diluted 1:5 with $1 \mathrm{mM} \mathrm{NaOH}$ and assayed in a fluorescence plate reader (Genesis Plus, TECAN, Germany) at excitation and emission wavelengths of 485 and $530 \mathrm{~nm}$, respectively. During the experiment, TER was measured to monitor the cell monoand bilayer integrity. The transport studies after TNF- $\alpha$ exposure were carried out in culture medium (RPMI, 10\% FCS).

The cumulative appearance of sodium-fluorescein in the acceptor compartment was plotted as a function of time. Apparent permeability coefficients $P_{\text {app }}$ were calculated using the equation: $P_{\text {app }}=$ $\left(1 /\left(A * C_{0}\right)\right) *(\mathrm{~d} Q / \mathrm{d} t)$, where $A$ is the surface area of the filter $\left(0.33 \mathrm{~cm}^{2}\right), C_{0}$ the initial concentration of sodium-fluorescein in the donor fluid and $Q$ the amount of drug passing across the cell layer.

\section{Electron Microscopy}

For transmission electron microscopy (TEM), the cell layers cultured on filter membranes were fixed in $2.5 \%$ glutaraldehyde in cacodylate buffer ( $\mathrm{pH} 7.2$ ) for $2 \mathrm{~h}$, then fixed in $1 \% \mathrm{OsO}_{4}$ for $2 \mathrm{~h}$ and dehydrated in graded ethanol. After carrying the filter membranes with cells through propyleneoxid as an intermedium, the samples were embedded in agar 100 resin (PLANO, Wetzlar, Germany) and submitted to polymerisation at $60^{\circ} \mathrm{C}$ for $48 \mathrm{~h}$. Semithin and ultrathin sections were cut perpendicular to the filter surface with an ultramicrotome (Leica, Bensheim, Germany) and ultrathin sections were placed onto copper grids. Ultrastructural analysis and photomicroscopy were performed with a transmission electron microscope (model EM 410; Philips, Eindhoven, Netherlands). For scanning electron microscopy (SEM) the cells on the upper and lower surface of the filter membranes were fixed in $2.5 \%$ glutaraldehyde and $1 \% \mathrm{OsO}_{4}$ as described above. After dehydration in graded ethanol and air drying, specimens were placed on Leit C-covered metal plates (Neubauer, Münster, Germany), sputtered with gold in a coating unit (model E5100, Polaron Instruments Inc., Munich, Germany), and analysed under a scanning electron microscope (model DSM962, Carl Zeiss Inc., Oberkochen, Germany).

\section{Exposure to the Proinflammatory Cytokine TNF- $\alpha$}

Cocultures were exposed to TNF- $\alpha$ (Sigma, $300 \mathrm{U} / \mathrm{ml}$ ) on the apical or basolateral surface on day 9 for further $48 \mathrm{~h}$. A volume of $190 \mu \mathrm{l} \mathrm{TNF}-\alpha(300 \mathrm{U} / \mathrm{ml})$ in RPMI 10\% FCS with Dex was added to the apical surface (upper well, NCI H441) or, in case of a basolateral exposure, $1 \mathrm{ml} \mathrm{TNF}-\alpha(300 \mathrm{U} / \mathrm{ml})$ in HPMEC medium was given to the lower well (HPMEC). The corresponding opposite side of the coculture was exposed to culture medium without cytokine. After $24 \mathrm{~h}$ the medium was changed, whereby one fraction of the cocultures was continuously exposed to TNF- $\alpha$ and the other fraction was exposed to fresh culture medium to evaluate the recovery of TER. Therefore, the cocultures were washed once with culture medium, and culture medium without cytokine was added to the upper and lower well. Development of TER was measured after $4,12,24$ and $48 \mathrm{~h}$, permeation of sodiumfluorescein was measured after $48 \mathrm{~h}$.

\section{Results}

\section{Characterization of Cellular Phenotypes}

HPMEC, isolated with CD 31 microbeads, exhibited lung microvascular endothelial cell-specific markers as previously described. ${ }^{44-46}$ The phenotype was observed in HPMEC-medium at least until passage 5. In our experiments, HPMEC up to passage 4 were utilized. The human adenocarcinoma cell lines A549 and NCI H441 exhibited osmiophilic intracellular bodies, demonstrated by staining with osmium and tannic acid. In TEM cross-sections, A549 showed a high amount of lamellar bodies (20-30/ cell), secretory organelles characteristic of alveolar type II cells, whereas in NCI H441 the number of multivesicular bodies (MVB) vs lamellar bodies (LB) was higher (Table 1).

Immunofluorescent staining of NCI H441 gave positive expression of all investigated markers for human alveolar type II cells, like TTF-1 and the production of the surfactant proteins SP-A, SP-B, SP-C and SP-D. An expression of TTF-1 could not be shown in A549 (Table 1). HPMEC did not exhibit any of the investigated epithelial markers and stained positive for VE-cadherin (Table 1). Both epithelial cell lines stained positive for the epithelial cadherin, E-cadherin. HPMEC, A549 and NCI H441 showed a positive but varying immunostaining of ZO-1 (Table 1). The expression pattern of ZO1 within the different cell types is described below.

\section{Effects of Dex on TER}

The development of TER for A549 in monoand coculture with HPMEC with and without Dex ( 1 and $2 \mu \mathrm{M}$ ) is depicted in Figure 1. In monoculture, A549 reached maximum TER-values of approximately $9 \Omega \mathrm{cm}^{2}$ on HTS 24-Transwell ${ }^{\circledR}$ filter plates. A coculture with HPMEC did not significantly increase the TER (maximum of $9 \pm 2.3 \Omega \mathrm{cm}^{2}$ on day 7). Treatment of the cocultures with different 
Table 1 Characterization of HPMEC and the investigated epithelial cell lines (A549 and NCI H441) by immunofluorescence staining and TEM

\begin{tabular}{lccc}
\hline Marker & \multicolumn{3}{c}{ Celltype } \\
\cline { 2 - 4 } & HPMEC & A549 & $H 441$ \\
\hline LB & - & $20-30^{\mathrm{a}}$ & $3-6^{\mathrm{a}}$ \\
MVB & - & $1-5^{\mathrm{a}}$ & $5-10^{\mathrm{a}}$ \\
SP-A & - & ++ & ++ \\
SP-B & - & + & ++ \\
SP-C & - & ++ & + \\
SP-D & - & ++ & + \\
TTF-1 & - & - & ++ \\
E-cadherin & - & \pm & + \\
VE-cadherin & + & - & - \\
ZO-1 & + & \pm & ++ \\
\hline
\end{tabular}

${ }^{\mathrm{a}}$ Counts per cell cross-section.

- , represents no; \pm , a fragmental; + , a moderate and ++ , a strong staining reaction with fluorochrome.

concentrations of Dex ( 1 and $2 \mu \mathrm{M}$ ) led to a slight increase in TER to maximum values of $24 \pm 1.6 \Omega \mathrm{cm}^{2}$ on day $10-11$ of cocultivation. The gradual development of TER-values for mono-cultures of NCI H441 and HPMEC as well as NCI H441 in coculture with HPMEC is depicted in Figure 1b, demonstrating data from one representative experiment showing the mean ( \pm s.d.) of 12 individual Transwells. After an initial delay of 6 days, TERvalues markedly increased for the Dex-treated cultures. A maximum of $565 \pm 48 \Omega \mathrm{cm}^{2}$ was attained for the coculture under treatment with $1 \mu \mathrm{M}$ Dex on day 11 of cocultivation. For the mono-culture of NCI $\mathrm{H} 441$ only values of $218 \pm 93 \Omega \mathrm{cm}^{2}$ could be attained under the same conditions. After an average maximum on day 10-12 for Dex-treated cocultures of NCI H441 and HPMEC, resistance values decreased slowly to values around $450 \pm 62 \Omega \mathrm{cm}^{2}$ on day 13 . In contrast, cocultures of NCI H441 with HPMEC without Dex did not develop a peak electrical resistance over a period of 13 days (Figure 1b). TER-values increased to a value of $44 \pm 5 \Omega \mathrm{cm}^{2}$. The steady increase closely followed the increase in cell number (see light micrographs (LM) picture Figure 2f). H441 in monoculture without Dex exhibited low TER-values around $12 \pm 4 \Omega \mathrm{cm}^{2}$. The induction of TER was only achieved in coculture medium with FCS and $1 \mu \mathrm{M}$ Dex while medium with insulin, transferrin, selenious acid (each with $0.625 \mathrm{mg} / \mathrm{ml})$, BSA $(125 \mathrm{mg} / \mathrm{ml})$, linoleic acid $(0.535 \mathrm{mg} / \mathrm{ml})$ as serum substitute (ITS $\left.{ }^{+}, \mathrm{BD}\right)$ and $1 \mu \mathrm{M}$ Dex did not show an increase in TER (data not shown). Therefore, all further experiments were carried out in medium supplemented with FCS and $1 \mu \mathrm{M}$ Dex.

To validate our measurement data, madin darby canine kidney (MDCK) cells were used as positive control cells, showing average TER-values of $8000 \pm 40 \Omega \mathrm{cm}^{2}$ after 7-14 days in mono-culture.
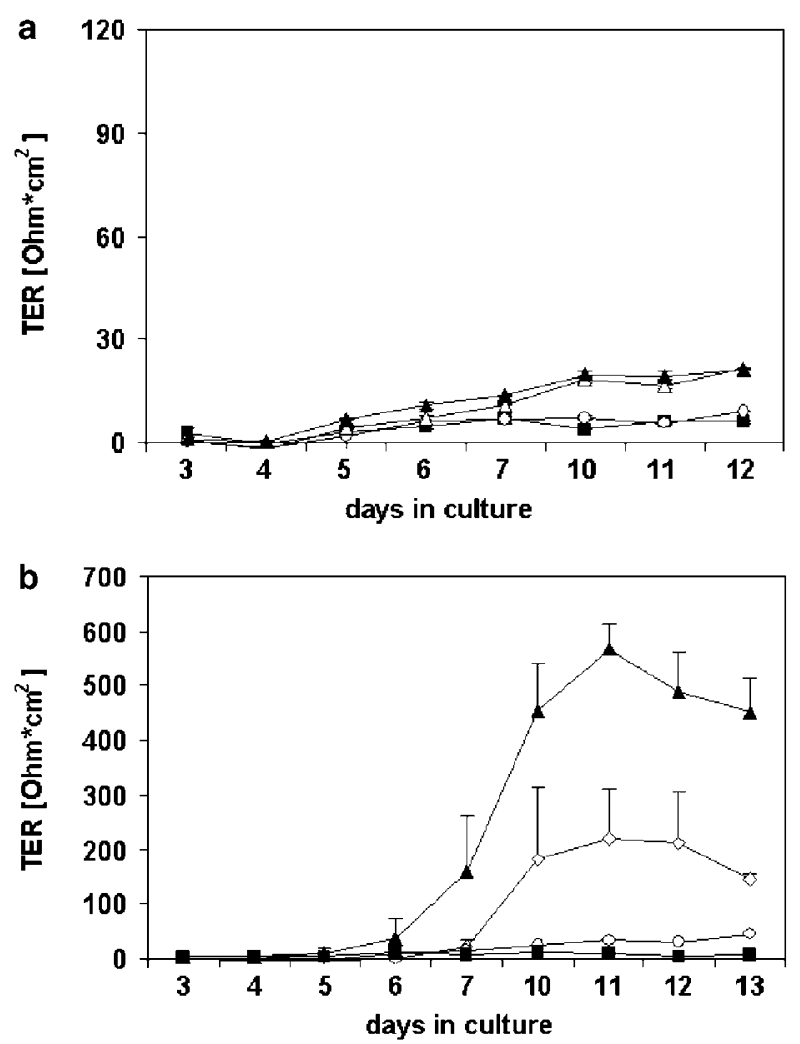

Figure 1 Time course of the development of TER: (a) monocultures of A549 and cocultures of A549 with HPMEC, (b) monocultures of NCI H441 and cocultures of NCI H441 cells with HPMEC. Cells were seeded at a density of $2 \times 10^{4} \mathrm{cells} / \mathrm{cm}^{2}$ on HTS 24-Transwell ${ }^{\circledR}$ filter plates and cultured without Dex in monoculture ( $\boldsymbol{\square})$ and in coculture with HPMEC ( $\bigcirc)$. Dex was supplemented on day 3 in monoculture $(\diamond)$ and in coculture with HPMEC at a concentration of $1 \mu \mathrm{M}(\boldsymbol{\Delta})$ and $2 \mu \mathrm{M}(\triangle)$. Each data point represents the mean \pm s.d. ( $n=4$ and 12 for A549 and NCI H441, respectively).

\section{Effects of Dex on Morphology}

Addition of Dex to the culture medium in the upper well produced marked changes in the morphology of A549. Compared to nontreated conditions, the cellular shape changed from a cuboidal (Figure 2a) to a more flattened morphology with adjacent cells being closer together (Figure 2b). LM examination of methylene blue-stained semithin sections revealed tighter contacts between neighbouring cells under Dex-treatment (Figure 2b, asterisk compared with Figure 2a,c arrowhead), but no tight junctional structures were visible in TEM (data not shown). In addition, with Dex a mono- to bilayer formation of A549 was achieved vs a local multilayer formation (two to three cellular layers) without Dex after 12 days of cocultivation (Figure $2 b$ and $c$ ).

No marked change of the cellular shape of NCI H441 was observed in Dex-treated cocultures of NCI H441 with HPMEC. The cells showed a cuboidal morphology with and without Dex (Figure 2d-f). The most obvious effect of Dextreatment on morphology was the maintenance of a 

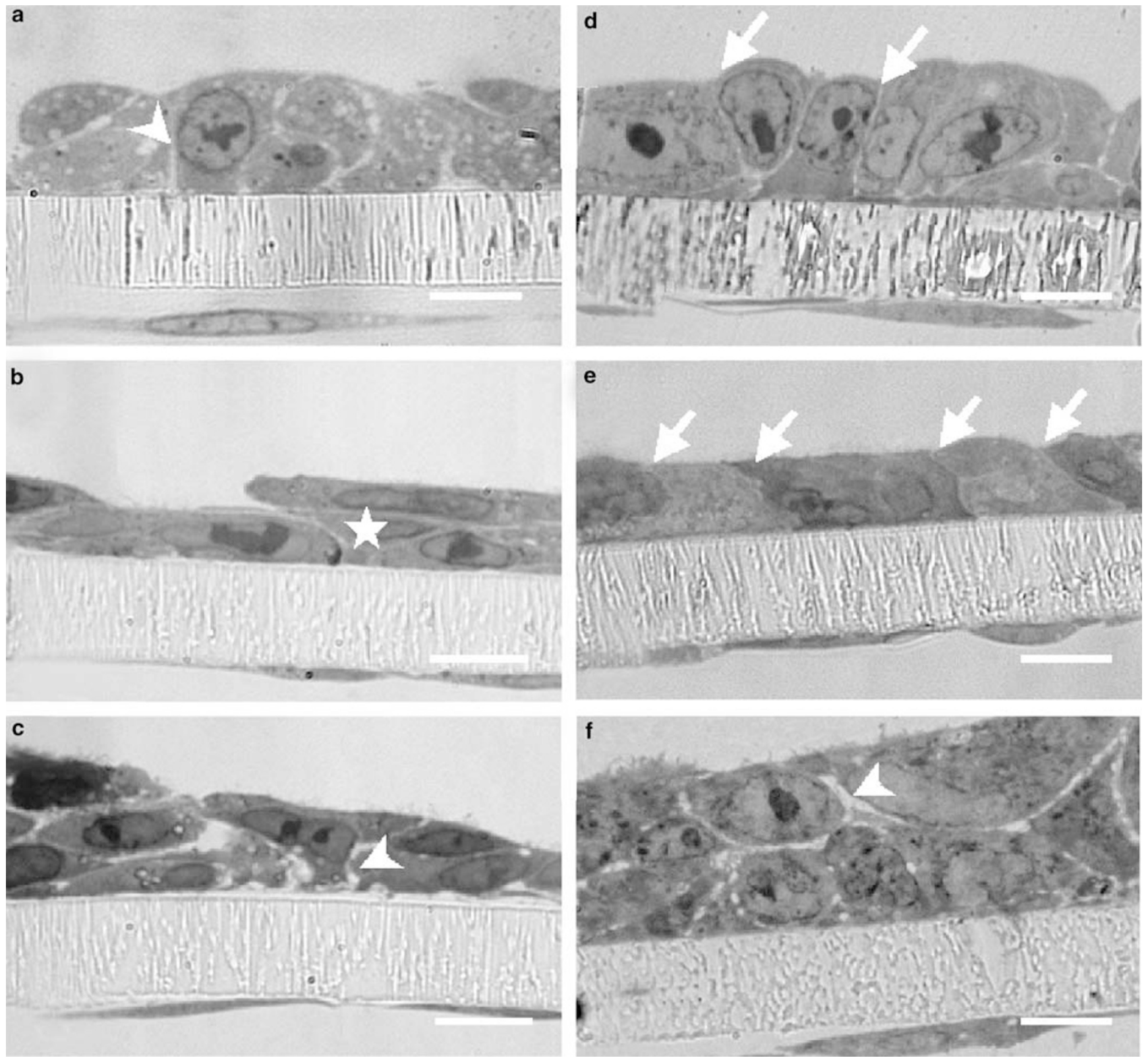

Figure 2 Light micrographs of the cocultures of A549 and HPMEC (lower surface of the filter membrane) without Dex at day 8 (a) and day 12 (c) and with $2 \mu \mathrm{M}$ Dex at day 12 (b). Cocultures of NCI H441 and HPMEC without Dex at day 8 (d) and day 12 (f) and with $1 \mu$ M Dex at day 12 (e). Nontreated A549 showed a wider paracellular space after 8 days compared to NCI H441 ((a), arrowhead compared to (d), arrow). Close cell-cell contacts were established in Dex-treated A549 ((b), asterisk) and NCI H441 ((e), arrows) after 12 days of coculture. Local multilayer formation on day 12 in nontreated A549 (c) and NCI H441 (f) was accompanied by wider paracellular spaces ((c), (f), arrowhead). Methylene blue stained semithin sections (scale bar $=10 \mu \mathrm{m}$ ).

strictly organized cellular monolayer up to day 12 of coculture with apical tight cellular contact areas (Figure 2e, arrows). In contrast, the monolayer of NCI H441, which was formed up to day 7 of coculture in nontreated cocultures (Figure 2d), was mostly replaced by a disorganized multilayer of NCI H441 on day 12 (Figure 2f).

The HPMEC on the lower surface of the filter membrane formed flattened monolayers. If the protruding nuclei of HPMEC were not cut in semithin sections, the endothelial cells could only be recognized by their fine cytoplasmic extensions.
As these extensions were extremely fine and were often easily destroyed by the sectioning procedure, an assessment of the integrity of the endothelial layer required further methods, such as SEM and immunofluorescence staining (see Figure 3i-l).

\section{Influence of Dex on the Formation of Tight and AJ}

The different cocultures (A549 with HPMEC and NCI H441 with HPMEC) were examined by immunofluorescence for the expression of structural 


\section{ZO-1}
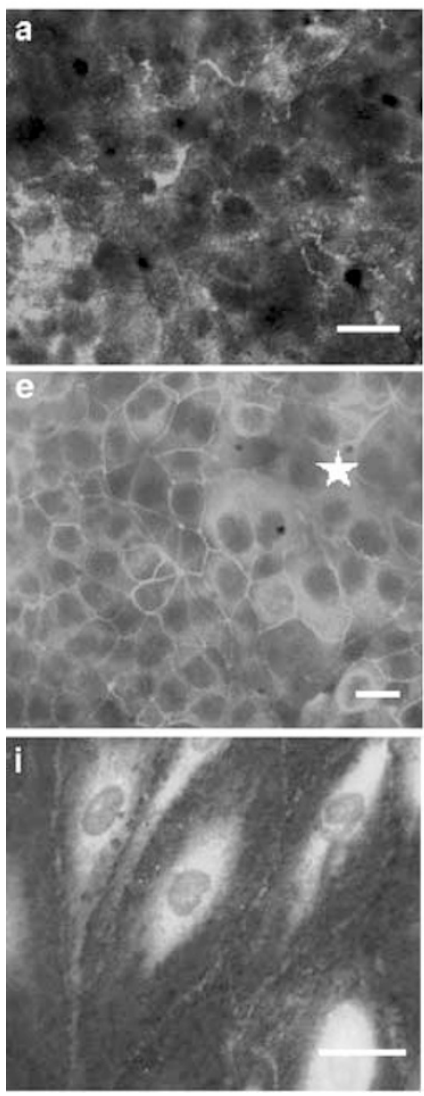
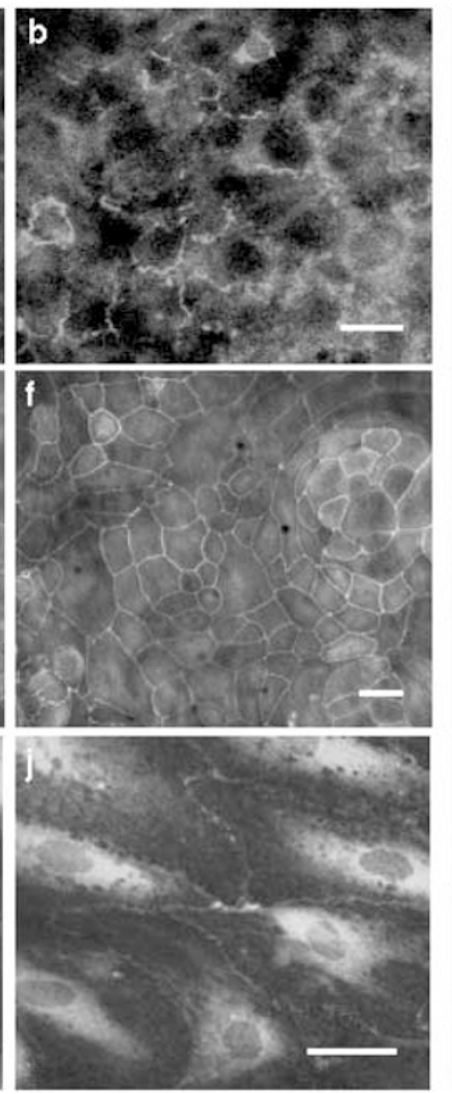

E- / VE-cadherin
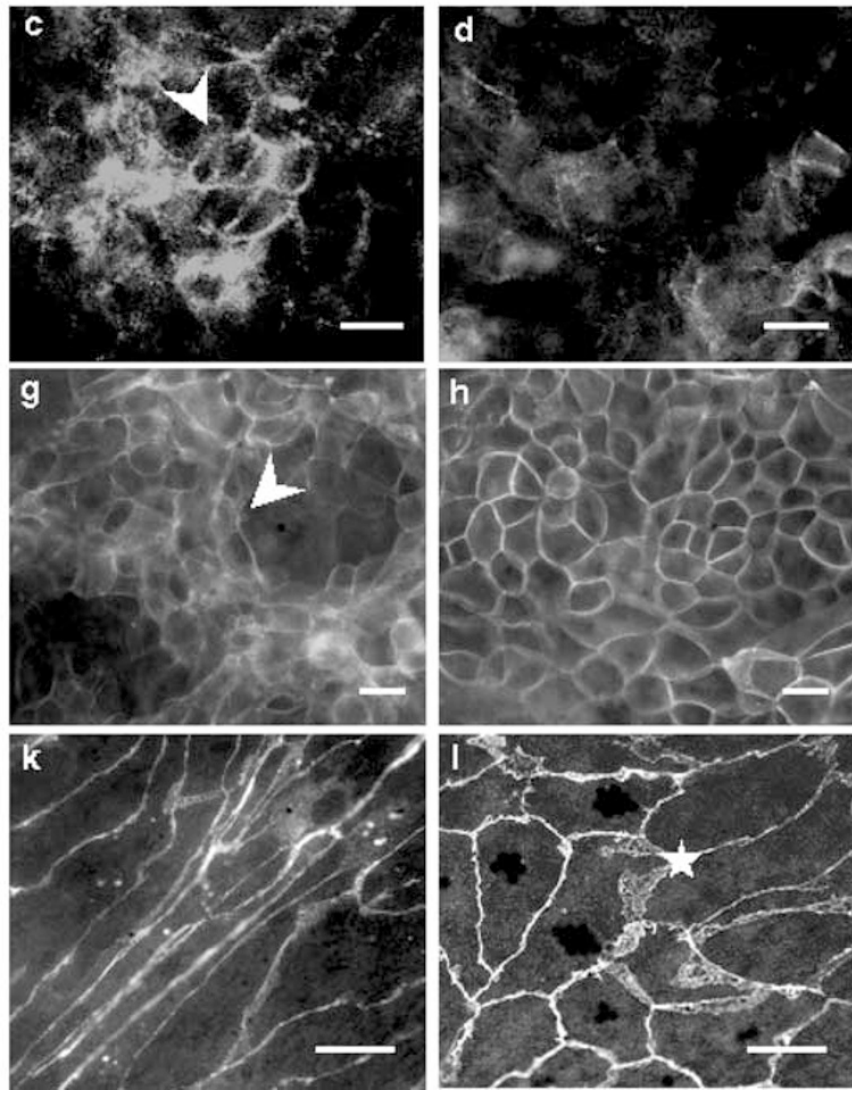

Figure 3 Immunofluorescent labeling of intracellular junctions in NCI H441 and A549 in coculture with HPMEC grown on costar filter supports treated (+Dex) or non-treated (-Dex) with $1 \mu \mathrm{M}$ Dex for 7 days (day 10 of coculture). The different cells studied are arranged as separate rows: A549 cells ((a)-(d)) NCI H441 cells ((e)-(h)) and HPMEC ((i)-(l)). The two investigated types of intercellular junctions TJ and AJ are depicted in separate columns. The columns labelled ZO-1 show polyclonal antibody staining directed against the TJ protein ZO-1 without ((a), (e), (i)) and with $1 \mu \mathrm{M}$ Dex ((b), (f), (j)). The columns labelled VE-/E-cadherin show AJ visualized using an antibody against E-cadherin for the epithelial cell lines without $((\mathbf{c}),(\mathbf{g}))$ and with $1 \mu \mathrm{M}$ Dex $((\mathbf{d})$, (h)) and an antibody against VE-cadherin for HPMEC without $((\mathbf{k}))$ and with $1 \mu \mathrm{M}$ Dex (l) (scalebar $=10 \mu \mathrm{m})$. Nontreated A549 cells form a multilayer on day 10 of cocultivation with a punctate paracellular staining of E-cadherin ((c), arrowhead), whereas with Dex the staining is fragmented. NCI H441 without Dex show areas of reduced circumferential und enhanced paracellular ZO-1 ((e), asterisk) staining. The multilayer growth of nontreated NCI H441 leads to a disorganized E-cadherin staining pattern ((g), arrow). Dex-treated NCI H441 form a well-organized monolayer with a regular paracellular staining of ZO-1 (f) and E-cadherin (h). HPMEC in coculture with Dex-treated NCI H441 establish a resting endothelial phenotype with VE-cadherin superstructures (l).

markers involved in TJ and AJ formation. This was performed on day 10 of cocultivation (cultivation time with high TER-values). The cellular layers on both sides of the Transwell filter membranes were fixed, permeabilized and immediately stained either with antibodies against the TJ protein ZO-1 or the AJ proteins E-cadherin and VE-cadherin on epithelial and endothelial cells, respectively.

In A549 cells cultured without Dex, the ZO-1 staining appeared perinuclear and as punctate aggregates and was occasionally present at cell-cell contacts (Figure 3a). In comparison, in the presence of Dex the junctional ZO-1 localization is slightly more distinctive, but still fragmented (Figure 3b). Concurrent with the disorganized distribution of ZO-1, E-cadherin was found primarily at the cellular junctions of cells developing multilayer structures (Figure 3c arrowhead). Multilayer formation of cell growth was verified by a nuclear counterstain shown as overlapping nuclei (data not shown). Dex-treated cultures with sparsely overlapping nuclei and mono- to bilayer formation of A549 (Figure 2b) showed little or no junctional staining of E-cadherin (Figure 3d). In contrast, Dex-treated NCI H441 cells exhibited an intense and uniform staining pattern of E-cadherin, localized to the lateral membranes of an organized epithelial monolayer (Figure 3h). Coincident with the distinct immunostaining of E-cadherin, ZO-1 staining was localized to the cell periphery in a sharp continuous band surrounding each cell at its apical border (Figure 3f). Immunofluorescence demonstrated that in the absence of Dex the layer of NCI H441 cells appears more disorganized, corresponding to a local enhanced perinuclear and discontinuous junctional staining of ZO-1 (Figure 3e, asterisk). The nuclear 
counterstain showed areas of overlapping next to evenly distributed nuclei. This 'hill and valley' formation of cell growth (Figure $3 \mathrm{~g}$ arrowhead, $4 \mathrm{~b}$ arrow) resulted in a nonuniform E-cadherin staining pattern (Figure 3g).

A representative $\mathrm{ZO}-1$ and $\mathrm{VE}$-cadherin staining of HPMEC in coculture with NCI H441 is presented in Figure 3 (Figure $3 \mathrm{i}-\mathrm{l}$ ), similar results were observed with A549 (data not shown). Primary HPMEC up to passage 5 retained their contactinhibited growth pattern independent of Dex-treatment. ZO-1 staining showed no significant difference with or without Dex and appeared as a perinuclear or fine continuous punctate staining at the cellular junctions (Figure $3 \mathrm{i}$ and $\mathrm{j}$ ). In contrast, a different pattern of staining was observed for VEcadherin in the presence or absence of Dex. In coculture with Dex-treated epithelial cells, HPMEC established a well-organized monolayer with cobblestone morphology and a pronounced VE-cadherin production at the cell-cell borders (Figure 31). Additionally, several VE-cadherin superstructures (Figure 3l, asterisk) were observed, resembling a netlike distribution of VE-cadherin at overlapping junctional areas of adjacent highly confluent endothelial cells. ${ }^{47}$ In non-Dex-treated cultures, HPMEC exhibited a fine circumferential staining pattern for VE-cadherin and the cell shape was more elongated (Figure 3k).

\section{Electron Microscopy of Cocultures of NCI H441 and HPMEC}

In the coculture of NCI H441 with HPMEC, the Dextreated induction of TER corresponded to an organized junctional appearance of ZO-1 and Ecadherin in NCI H441 (Figure $3 f$ and $h$ ) and a resting phenotype of HPMEC, with VE-cadherin superstructures (Figure 3l). To determine whether Dex induced further morphological differentiation, we examined the coculture at different time points by electron microscopy.

\section{Scanning Electron Microscopy}

In nontreated NCI H441, a confluent monolayer with rounded cells, protruding nucleoli and apical microvilli was established by day 7 of cocultivation (Figure 4a). The appearance of 'hills and valleys' depicted in the SEM view on day 11 (Figure 4b, arrow) was most likely due to a multilayer configuration. On day 14, the nontreated NCI H441 formed a totally disorganized surface structure with less microvilli and cytoplasmic pseudopodia covering adjacent cells (Figure 4c, arrow). Observed on days 7 and 11, HPMEC on the opposite side of the Transwell filter membrane established monolayers with most cells showing an elongated shape. On day 14, the layer of HPMEC appeared disrupted in the nontreated coculture (data not shown).
Dex-treated NCI H441 maintained a morphology consistent with an even monolayer for the entire cocultivation period. On day 7, a confluent monolayer of flattened cells with protruding nucleoli, welldefined cellular contact areas (Figure $4 \mathrm{~d}$, arrow) and apical microvilli was observed. During the course of cocultivation with Dex, the cells began to round up, but still kept their organized structure with visible apical cellular contacts and a well-established microvillous coverage (Figure $4 \mathrm{e}$ and f). Concurrent with the immunofluorescent findings for the Dex-treated coculture, the HPMEC established a confluent monolayer, showing flattened cells with wide cytoplasmic expansions and protruding nucleoli. The quiescent cobblestone-morphology of HPMEC remained during the entire cocultivation period (data not shown).

\section{Transmission Electron Microscopy}

Cross-sections were prepared on day 10 of cultivation by cutting the cocultures in the $y-z$ axis and were viewed by TEM to morphologically examine TJ formation under Dex-treated and nontreated conditions (Figure 5). In both, the presence and the absence of Dex, NCI H441 established a cuboidal morphology with apical microvilli and a basolateral differentiation (Figure 5a and c). The HPMEC on the opposite side showed a typical flattened morphology with a protruding nucleus and long cytoplasmic expansions (Figure 5a and c). Under higher magnification the Dex-treated NCI H441 exhibited a reorganization of the apical junction, consisting of a TJ and AJ complex accompanied by a desmosome (Figure 5d). In contrast, in the absence of Dex, focal and nonspecific areas of separation between adjacent cells were observed (Figure 5b, asterisks). HPMEC on the opposite side of the filter membrane formed an even monolayer under both conditions on day 10. At higher magnification, HPMEC grown on the opposite side of Dex-stimulated NCI H441 established several lateral contacts between adjacent cells on day 10 of cocultivation (Figure 6a-c). The endothelial cells developed close cell-cell contacts with a narrow paracellular space and well-defined AJ. TJ are visible as punctate focal contacts (Figure 6a, asterisk), appearing to a lesser extent than AJ.

\section{Reproducibility of the Development of a Functional Barrier}

A similar maximum development of TER was found for Dex-treated cocultures at days 10-12 of cocultivation. In order to evaluate the reproducibility of the in vitro model system, we summarized the TERvalues from three different HPMEC isolates with NCI H441 or A549 on day 11 of each individual cocultivation assay. The mean TER-values ( \pm s.d.) for Dex-treated and nontreated mono- and cocultures $(n=24)$ on day 11 of cultivation are depicted in Figure 7. Dex-treated monocultures of NCI H441 

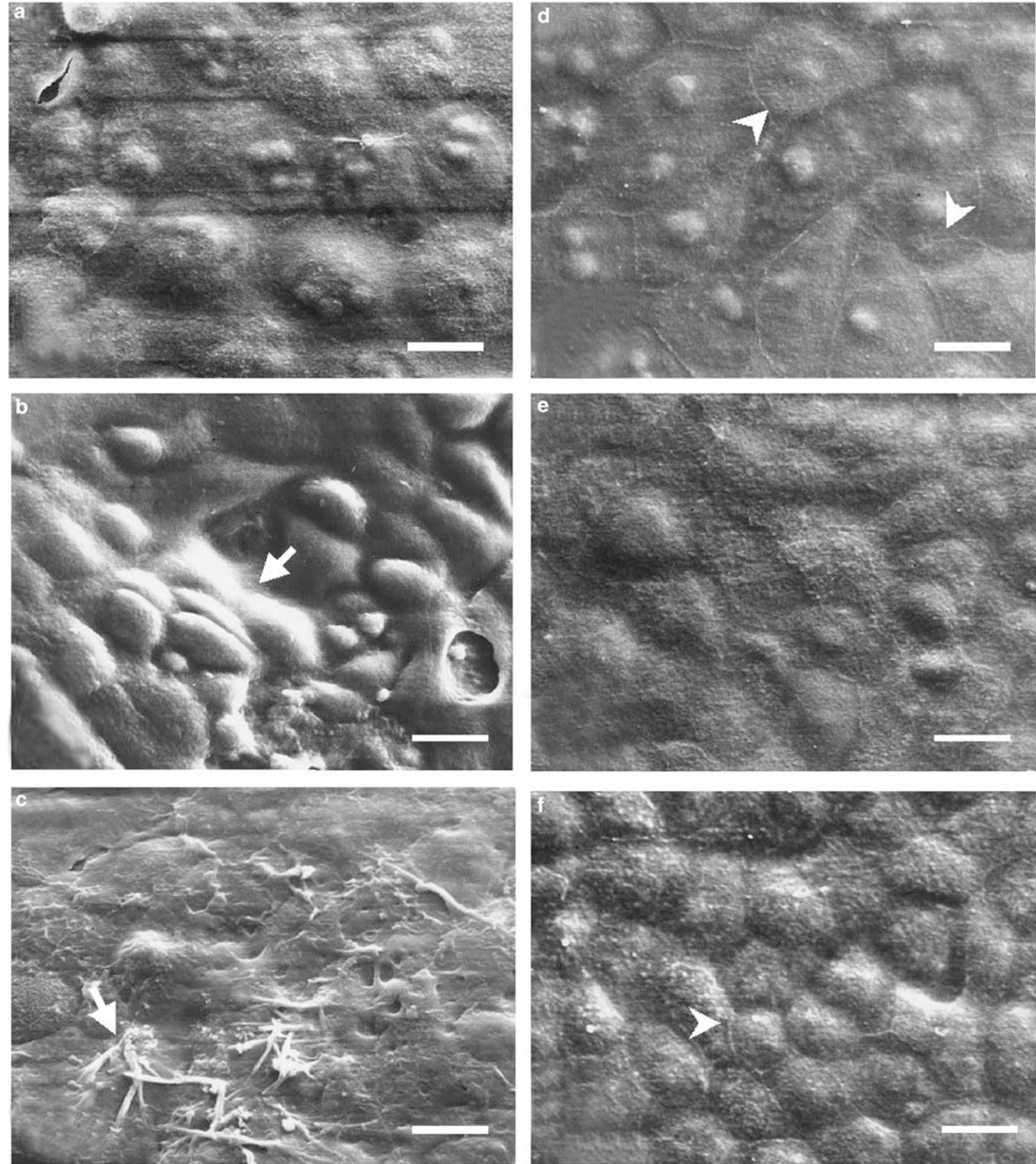

Figure 4 SEM of NCI H441 cells grown in coculture with microvascular endothelial cells on collagen-treated HTS 24-Transwell filter plates. Cocultures were grown in RPMI 10\% FCS without Dex (left) and with $1 \mu \mathrm{M}$ Dex (right) starting at day 3 . At different time points the filters were fixed with $2.5 \%$ GA and prepared for REM on day 7 ((a), (d)), day 11 ((b), (e)) and day 14 ((c), (f)). NCI H441 in non-treated cocultures showed a 'hill and valley' growth pattern on day 11 of culture $((\mathbf{b})$, arrow), whereas Dex-treated cells formed an even layer with well-developed microvilli (e). In Dex-treated NCI H441, the cellular contact areas were visible as protruding paracellular lines ((d), (f), arrowhead). (scale bar $=10 \mu \mathrm{m}$ ). 
a

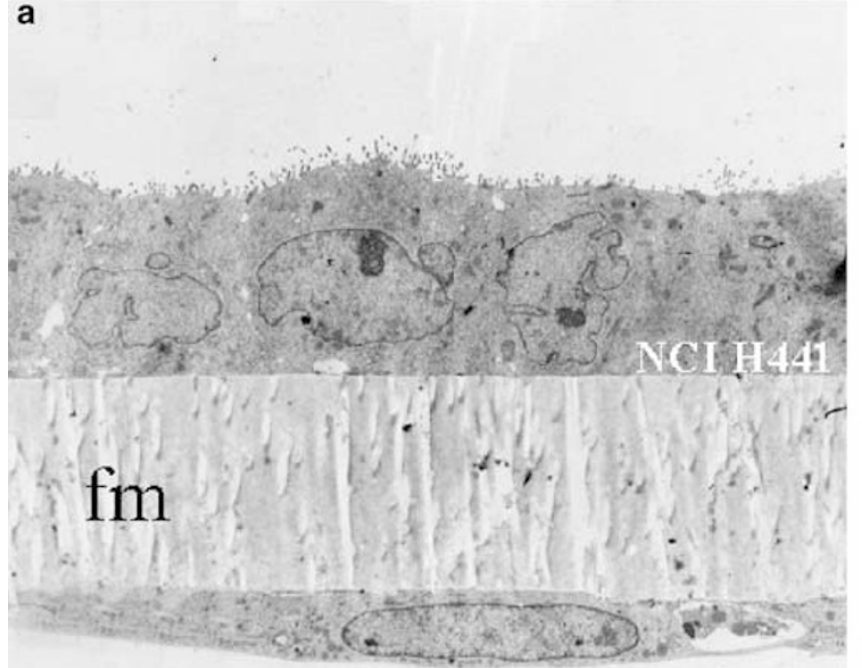

HPMEC

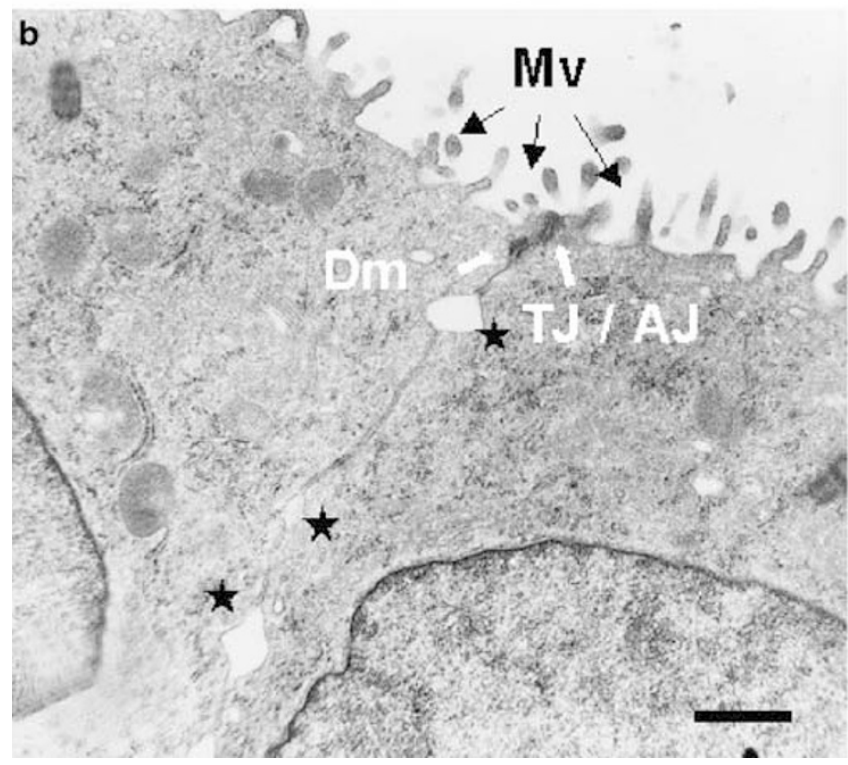

C
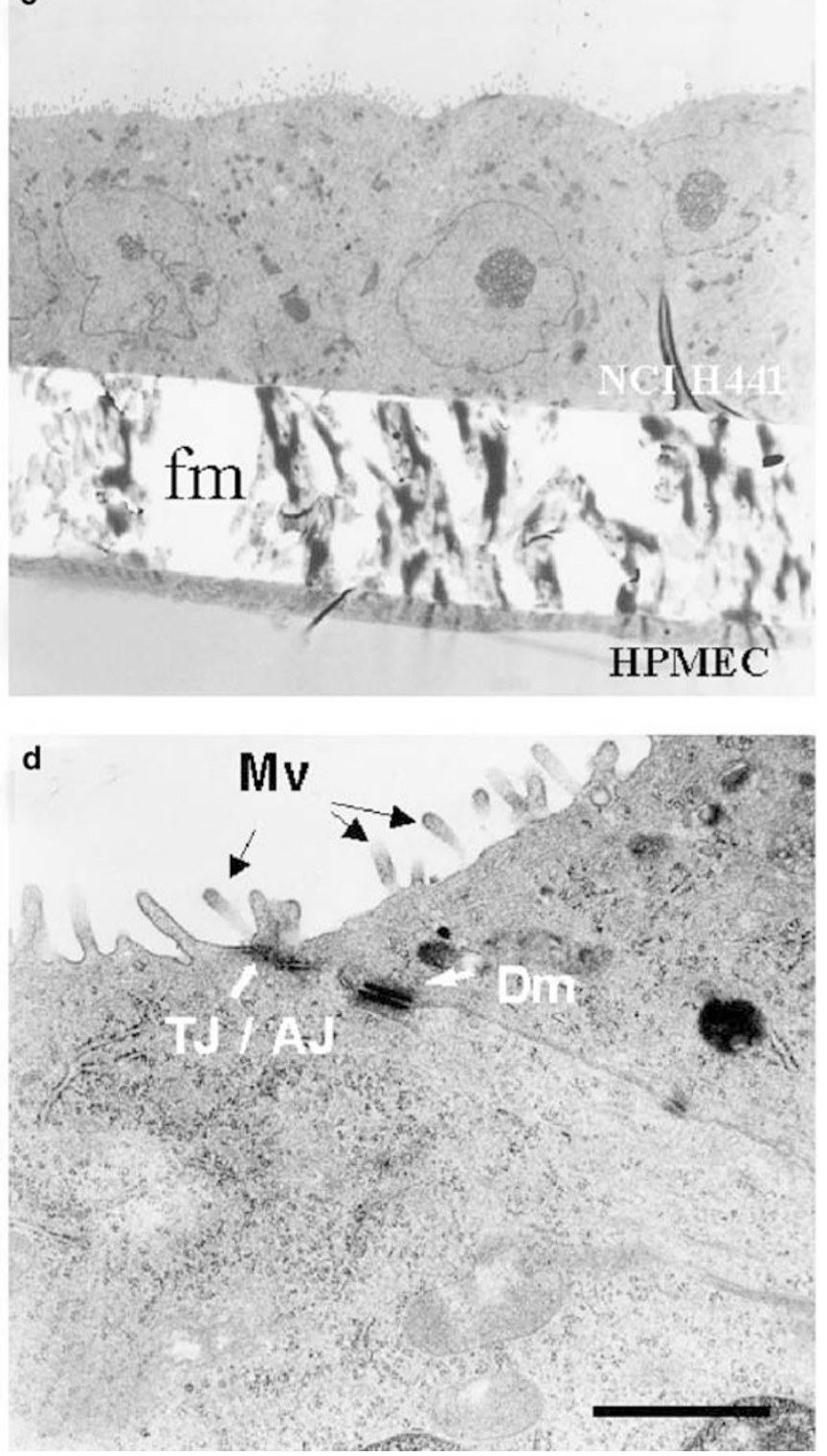

Figure 5 TEM micrograph of NCI H441 in coculture with HPMEC on the upper and lower surface of the polycarbonate filter membrane. Cocultures grown without Dex ((a),(b)) or with $1 \mu \mathrm{M}$ Dex ((c), (d)) were fixed on day 10 of cocultivation. A magnification of NCI H441 on the upper side of the filter membrane shows apical cell contacts consisting of TJ accompanied by AJ and desmosomes (Dm) between two adjacent cells. The apical plasma membrane possesses several microvilli (Mv). NCI H441 with $1 \mu$ M Dex develop tight contacts of the plasma membranes (c), without Dex-treatment (b) NCI H441 show several areas where the membranes are separated (asterisk) (scale $\operatorname{bar}=1 \mu \mathrm{m})$.

showed a significant increase in TER-values from $44 \pm 3 \Omega \mathrm{cm}^{2}$ (nontreated) to $273 \pm 11 \Omega \mathrm{cm}^{2}$ (Dextreated). This represents a six-fold enhancement of TER in the presence of Dex. The TER-values of A549 (average $5 \Omega \mathrm{cm}^{2}$ ) could not be significantly increased in the presence of $1 \mu \mathrm{M}$ Dex. Cocultures of NCI H441 with HPMEC and $1 \mu \mathrm{M}$ Dex exhibited TER-values of $480 \pm 100 \Omega \mathrm{cm}^{2}$, illustrating a further significant 1.8-fold increase in TER compared to the Dex-treated monoculture of NCI H441. For Dextreated NCI H441 as well as for A549, a significant increase in TER-value was achieved through cocultivation with HPMEC.

\section{Paracellular Integrity}

To confirm that an increase in TER was an indicator of the formation of tight mono- and/or bilayers, we monitored the paracellular movement of the anionic hydrophilic marker, sodium-fluorescein, across Dextreated and nontreated monocultures of NCI H441, and cocultures of NCI H441 with HPMEC. The transport experiments were performed on day 11 of cultivation, 7 days after supplementation with $1 \mu \mathrm{M}$ Dex. The minimum paracellular permeability for sodium-fluorescein was $0.81 \pm 0.05 \times 10^{-6} \mathrm{~cm} / \mathrm{s}$ measured for the coculture under Dex-treatment 

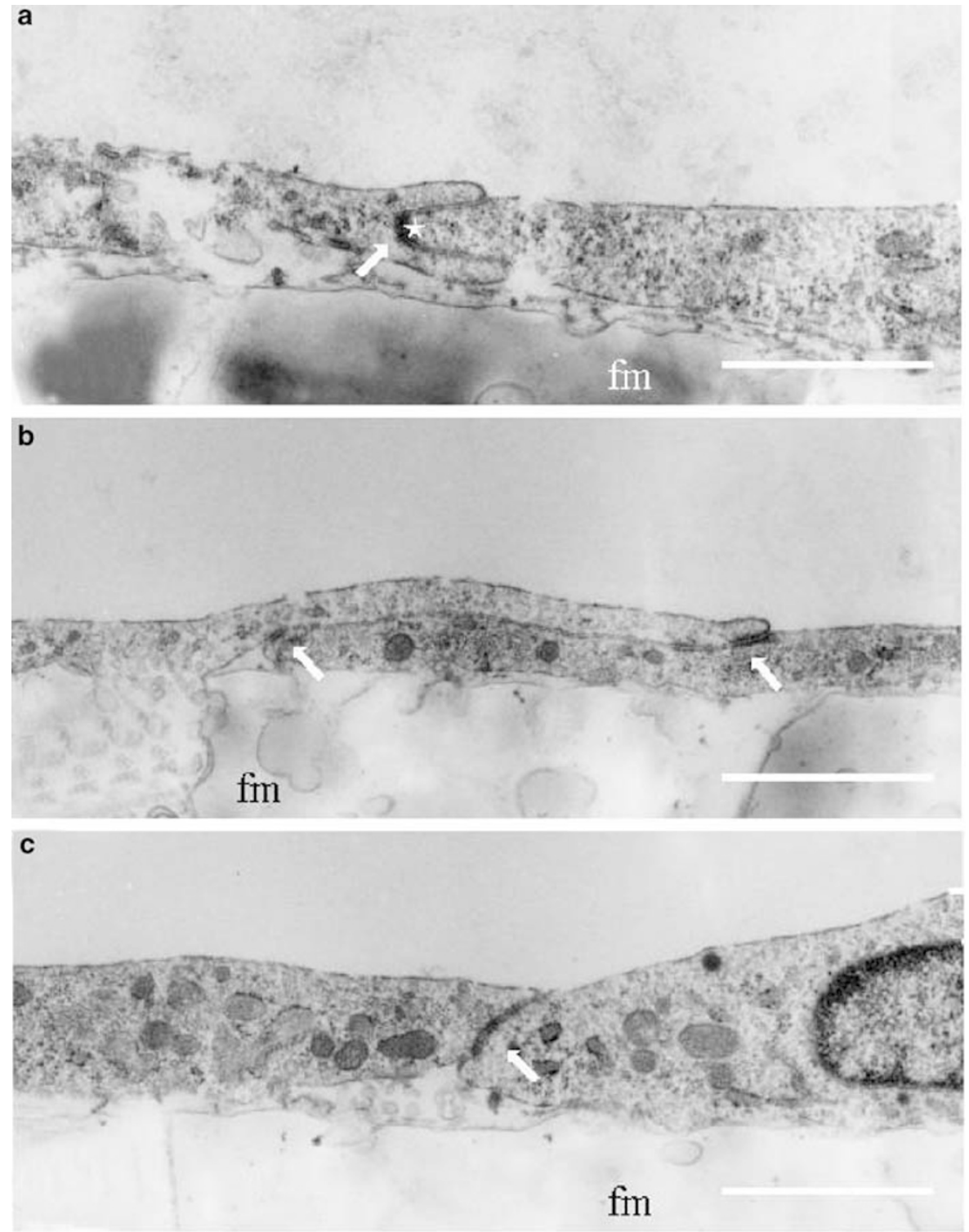

Figure 6 TEM micrograph of HPMEC cocultured with Dex-treated NCI H441 for 10 days on the lower and upper surface of the polycarbonate filter membrane. HPMEC exhibit the typical flattened morphology of endothelial cells with different lateral cell-cell contacts and a narrow paracellular space: (a) One cell is partly overlaping the adjacent cell forming an AJ contact (arrow) with a punctat TJ structure visible (asterisk). (b) The overlapping structure of one cell is connected to the underlying cell by AJ's (arrows). (c) Membranes are only apposed over a narrow strip with AJ (arrow) between the two adjacent cells. The basal surface of the cells (at the bottom of each micrograph) is attached to the filter membrane (fm). (scale bar $=1 \mu \mathrm{m})$.

(Table 2). On day 11, the apical to basolateral permeability was decreased approximately threeto four-fold in the presence of Dex for both the monoculture of NCI H441 and the coculture of NCI H441 with HPMEC. Under Dex-treatment, the coculture of NCI H441 with HPMEC showed another 1.4-fold decrease in permeability compared to the monoculture of NCI H441.

\section{Influence of TNF- $\alpha$ on Barrier Function and Paracellular Integrity}

In a preliminary study, the cocultures were exposed to the proinflammatory cytokine $\mathrm{TNF}-\alpha$ to determine whether basolateral or apical treatment with this proinflammatory cytokine could elicit effects on the TJ permeability of the Dex-treated coculture. We exposed the apical (upper well, epithelial side) and the basolateral (lower well, endothelial side) side of the coculture to TNF- $\alpha(300 \mathrm{U} / \mathrm{ml}$ or $732 \mathrm{pg} / \mathrm{ml})$ and determined the effects on TER at $4,12,24,48 \mathrm{~h}$ and $P_{\text {app }}$ at $48 \mathrm{~h}$. This concentration was chosen because it causes a significant induction of adhesion molecules like ICAM-1 and VCAM-1 as well as E-selectin on HPMEC. ${ }^{48}$ Furthermore, comparable concentrations in the range from $242 \pm 126^{35}$ to $10731 \pm$ $5048 \mathrm{pg} / \mathrm{ml}^{36}$ TNF- $\alpha$ were described in bronchiallavage from ARDS patients. 
After $24 \mathrm{~h}$ apical exposure to TNF- $\alpha$, there was no significant effect on TER compared to control. However, for cocultures exposed to TNF- $\alpha$ from the basolateral side, the TER-value at $12 \mathrm{~h}$ decreased to $74 \pm 4 \%$ and further decreased to $69 \pm 2 \%$ of control cocultures at $24 \mathrm{~h}$ (Figure 8a). After $48 \mathrm{~h}$, the apical exposed cocultures still exhibited TER-values that

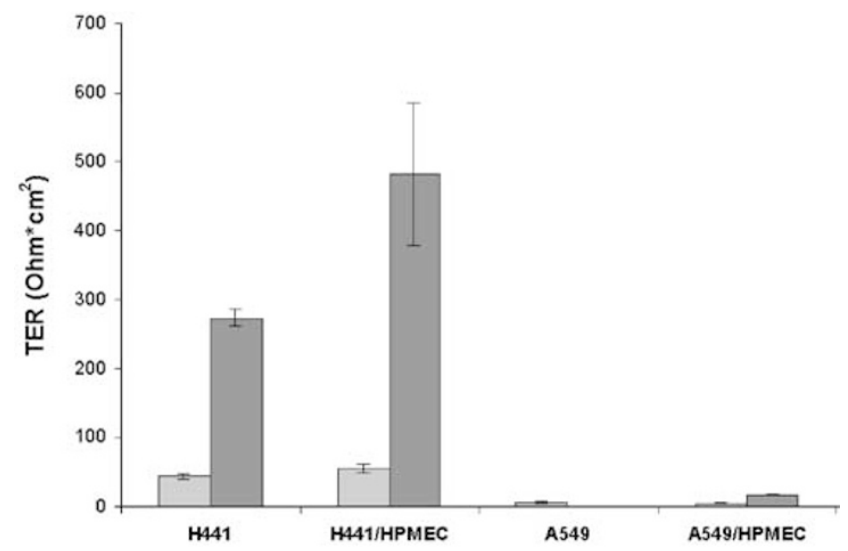

Figure 7 TER-values on day 11 of culture for monocultures of H441 and A549 and cocultures with HPMEC in medium without (light grey) and with $1 \mu \mathrm{M}$ Dex (dark grey). Each data point represents the mean \pm s.d. $(n=18)$ from three different assays.

Table $2 P_{\text {app }}$ values for the transport of sodium-fluorescein across cell layers of NCI H441 in mono-and in coculture with HPMEC. (data are shown as mean \pm s.d. $(n=4)$ )

\begin{tabular}{cccc}
\hline Solute & \multicolumn{4}{c}{$P_{\text {app }}\left(\times 10^{-6} \mathrm{~cm} / \mathrm{s}^{-1}\right)$} \\
\cline { 2 - 4 } & H441+ & Coculture & Coculture+ \\
& DEX & & DEX
\end{tabular}

$\begin{array}{lllll}\text { Sodium- } & 3.65 \pm 0.56 & 1.11 \pm 0.23 & 3.09 \pm 0.49 & 0.81 \pm 0.05\end{array}$

fluorescein

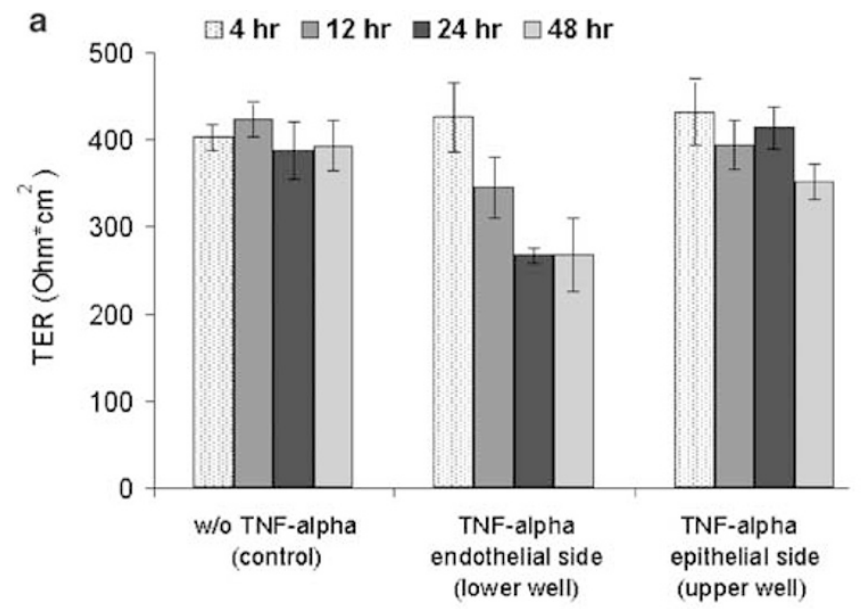

were slightly ( $91 \pm 5 \%$ ) but not significantly reduced compared to control, whereas TER in those exposed to TNF- $\alpha$ from the endothelial side decreased to $69 \pm 11 \%$ (Figure $8 \mathrm{a}$ ).

Upon basolateral removal of TNF- $\alpha$ at $24 \mathrm{~h}$, TER returned to control levels by $24 \mathrm{~h}$ post-treatment (Figure 8b). To correlate changes in TER-values induced after TNF- $\alpha$ treatment to alterations in the barrier function of the TJ, the permeability coefficients (apical to basolateral) of cocultures to sodium-fluorescein were measured after exposure. The transport experiments were performed on day 11 of cultivation, $48 \mathrm{~h}$ after starting the TNF- $\alpha$ treatment. We performed the transport experiments in culture medium (RPMI 10\% FCS) not to further irritate the stimulated cells by using serum-free KRB. The paracellular permeability for sodiumfluorescein averaged $0.170 \times 10^{-6} \mathrm{~cm} / \mathrm{s}$ measured for the coculture under Dex-treatment in culture medium (control w/o TNF- $\alpha$, Table 3). On day 11, the apical to basolateral permeability was increased by approximately $36 \%$ in the presence of TNF- $\alpha$ in the lower well (endothelial side) for the coculture of NCI H441 with HPMEC (Table 3). Coincident with no significant effect on TER compared to control after $48 \mathrm{~h}$ apical exposure to TNF- $\alpha$, the permeability for sodium-fluorescein was not significantly increased in the presence of TNF- $\alpha$ compared to control. Removal of TNF- $\alpha$ after $24 \mathrm{~h}$ showed a decrease in permeability at $48 \mathrm{~h}$ to control level for both the apical and the basolateral exposure (Table 3).

\section{Discussion}

We have developed a coculture system of human distal lung epithelial and primary microvascular endothelial cells in which stable and confluent

Figure 8 TER-values of cocultures (H441 with HPMEC) exposed to TNF- $\alpha$ (300 U/ml) compared to control without treatment. (a) Time course of the development of TER-values for basolateral (endothelial side, HPMEC) or apical (epithelial side, NCI H441) exposed cocultures at $4,12,24$ and $48 \mathrm{~h}$. (b) Recovery of TER $24 \mathrm{~h}$ after washing and removal of TNF- $\alpha$, which followed $24 \mathrm{~h}$ exposure to TNF- $\alpha$ [48 h (24 h TNF)] compared to the continuous exposure to TNF- $\alpha$ for 24 and $48 \mathrm{~h}$. Each data point represents the mean \pm s.d. $(n=3)$. 
Table $3 P_{\text {app }}$ values for the transport of sodium-fluorescein in RPMI 10\% FCS across cell layers of NCI H441 in coculture with HPMEC stimulated with and without (w/o) TNF- $\alpha(300 \mathrm{U} / \mathrm{ml})$ on day 9 of coculture for 24 and $48 \mathrm{~h}$, respectively (data are shown as mean \pm s.d. $(n=3))$

Solute sodium-fluorescein

$$
P_{a p p}\left(\times 10^{-6} \mathrm{~cm} / \mathrm{s}\right)
$$

Coculture w/o Coculture+TNF- $\alpha(300 \mathrm{U} / \mathrm{ml})$

TNF- $\alpha$ (control)

$0.181 \pm 0.021$

$0.159 \pm 0.015$

$48 \mathrm{~h}$ stimulation

$24 \mathrm{~h}$ stimulation and $24 \mathrm{~h}$

fresh medium on endothelial side

$0.247 \pm 0.026$

$0.176 \pm 0.025$
Coculture $+T N F-\alpha(300 \mathrm{U} / \mathrm{ml})$ on epithelial side

$0.228 \pm 0.034$

$0.197 \pm 0.031$ monolayers were cocultivated for 10-12 days on the upper and lower surface of collagen-coated HTS 24Transwell ${ }^{\circledR}$ filter membranes, establishing a functional barrier in a 24-multiwell test-system. This model mimics the layered interfaces of a lung-blood barrier and allows a cell-to-cell communication that influences the cellular morphology, differentiation, orientation and polarization.

The aim of our study was to establish a coculture system of distal lung epithelial cells and lung microvascular endothelial cells as an in vitro model to examine acute lung injury. To mimic the in vivo situation of an alveolocapillary unit, one of the main criteria of the in vitro coculture model was to establish a functional barrier. Since selective barrier function is involved in many aspects of normal lung physiology, the destruction of this barrier is a central element in pathological lung events. Acute lung injury for example is characterized by lesions of both lung alveolar epithelial (ATI and ATII) and endothelial cells. ${ }^{49}$ Within the alveolar epithelium, ATII cells play important roles in normal pulmonary function and in the response of the lung to toxic compounds that may cause lung damage. ${ }^{50}$ The pulmonary microvascular endothelium resembles a dynamic barrier that is critical for lung gas exchange and regulation of fluid and solute passage between the blood and interstitial compartments in the lung. ${ }^{51}$ Our coculture model should resemble the properties of both essential cell types involved in the formation of a lung-blood barrier and its reestablishment after injury, the ATII cells and the lung microvascular endothelium.

To mimic the organotypic characteristics of the human lung as accurately as possible in vitro, primary isolated pulmonary microvascular endothelial cells were used to establish the coculture. Although techniques have been developed to isolate and purify human adult ATII cells from lung tissue,,$^{51-55}$ transdifferentiation of the isolated cells leads to a rapid loss of the ATII phenotype within 8-10 days of cultivation towards an ATI-like phenotype. ${ }^{54,55}$ In comparison the cell line A549 $9^{56}$ does not transdifferentiate and is commonly used as a model for ATII cells. ${ }^{5,57-60}$ The cell NCI H441 line exhibits morphological characteristics of type II and Clara cells. ${ }^{61}$
Clara and ATII cells share several markers such as the production of surfactant proteins SP-A, SP-D, SP-B and the associated expression of the nuclear factor TTF-1. Beside these attributes, recent studies have shown that NCI H441 exhibited responses to mitogenic growth factors similar to primary isolated type II cells. ${ }^{62}$ In our studies, NCI H441 exhibited all investigated markers for type II cells, such as the expression of all surfactant proteins and TTF-1. The formation of lamellar bodies, storage organelles for SP-B and SP-C, and associated phospholipids, like dipalmitoylphosphatidylcholine (DPPC), ${ }^{63}$ and the positive immunocytochemical staining for the ATII marker SP-C further supports the type II characteristics of NCI H441. NCI H441 cells are commonly used as models of the Clara cell type, although these cells also exhibit a number of type II characteristics and could therefore be a useful in vitro model for these cells. Nevertheless, further characterization is necessary to determine if this cell line can be applied as an ATII model for each individual question.

The alveolar epithelium of the lung forms a much tighter barrier against liquid flux and protein permeation than the capillary endothelium. ${ }^{64}$ Therefore, a prerequisite for an in vitro-like model of a peripheral lung-blood barrier is the establishment of a tight epithelial cell monolayer distinguished by high TER-values. In previously described culture models, the human distal airway cell line A549 failed to develop substantial TER ${ }^{29,65}$ and showed TJ of a beaded appearance in freeze-fracture studies. ${ }^{26}$ However, A549 were used in all human coculture models for leukocyte transmigration or microbial infection at the distal airways, ${ }^{66,67}$ but the formation of a functional barrier was not adequately characterized. For transdifferentiated human ATI-like cells in mono-culture TER-values of more than $1000 \Omega \mathrm{cm}^{2}$ have recently been reported, ${ }^{54,55}$ whereas TERvalues as high as $2000 \Omega \mathrm{cm}^{2}$ for primary cultures of rat ATI-like cells have been cited. ${ }^{64}$ Rat ATII cells (culture 3 days) showed an average value of $762 \Omega \mathrm{cm}^{2,11}$ thus, we expected the establishment of TER-values around this level for an in vitro model of human alveolar type II epithelial cells with functional barrier properties. As epithelial TJ are highly dynamic, ${ }^{26}$ their assembly in vitro can be influenced 
by a variety of agents, such as hormones, drugs and metabolites $^{23,68}$ as well as external and internal $\mathrm{Ca}^{2+}$-concentration. ${ }^{69,70}$ Therefore, we studied the effect of the glucocorticoid Dex on the tightening of the epithelial barrier measured by TER. Independent of the modulation of culture conditions, A549 failed to show sufficient formation of a tight epithelial barrier. In contrast, the addition of Dex to monoand cocultures of NCI H441 and NCI H441 with HPMEC resulted in a significant enhancement of barrier function. We found a stimulation of barrier formation demonstrated by a six-fold increase in TER compared to nontreated conditions, similar to the results of Dex-treatment found for mammary epithelium. ${ }^{30}$ NCI H441 stimulated with Dex in coculture with HPMEC further established contactinhibited monolayers, showing a continuous, apical immunostaining of ZO-1 and well-organized circumferential E-cadherin staining. The polarized cuboidal architecture of the epithelium with apical junctional structures as well as the microvillous beat was established similar to that observed in vivo, as confirmed by TEM. Under Dex-treatment, the pattern shows reproducible maximum TERvalues of $480 \pm 100 \Omega \mathrm{cm}^{2}$ after $10-12$ days of cocultivation, whereas for a monoculture of NCI H441 maximum TER-values of $273 \pm 11 \Omega \mathrm{cm}^{2}$ could be achieved with Dex $(1 \mu \mathrm{M})$. In a functional test for paracellular restrictiveness, the coculture of NCI H441 and HPMEC demonstrated a significantly reduced flux of the hydrophilic permeability marker, sodium-fluorescein. These results indicate that Dex alone and DEX in the cocultivation of NCI H441 with HPMEC both induce the differentiation of NCI H441 and the formation of a tight barrier.

Comparing mono- and cocultures, enhanced TERvalues were measured in coculture compared to the monoculture of NCI H441. These findings may be due to paracrine factors influencing the neighbouring cell type in coculture or due to Dex-treatment. ${ }^{71-74}$ The effects of Dex may not only be restricted to the epithelial cells but may also have an influence on the endothelial cells in coculture. Although in our experiments Dex was only applied to the epithelium in the upper chamber of the HTS 24-Transwell ${ }^{\circledR}$ unit, an effect by Dex on the endothelium via diffusion through the epithelial layer cannot be ruled out. Dex has previously been shown to induce intercellular junctions, gaps and ZO-1 in endothelial cells of the tabecular meshwork and Schlemm's canal of the eye. ${ }^{75}$ Apart from the formation of a resting or quiet endothelial monolayer with pronounced VE-cadherin staining, no additional changes on endothelial ZO-1 staining were observed with Dex in our experiments. Nevertheless, the enhanced TER-values in coculture compared to the monoculture could be due to the formation of a tighter epithelial barrier, and possibly due to the establishment of a second tight barrier, the endothelial barrier. Further studies are planned to address these findings.
Better knowledge of the structure and function of the intercellular junctions between constituent cells of the alveolar epithelium and endothelium is critical for understanding how the individual barriers are injured and re-established after injury. Studies are needed to characterize the proteins that make up the TJ, their relationships with the cytoskeleton, and the effect of injury on TJ structure and functional relationships. ${ }^{76}$ To demonstrate the applicability of our coculture as a model for an injured and re-established distal lung barrier, we tested the influence of the proinflammatory cytokine TNF- $\alpha$ on TER and paracellular permeability. Our preliminary study showed a significant difference between a basolateral and apical exposure to TNF- $\alpha(300 \mathrm{U} / \mathrm{ml})$, with reduced TER-values after basolateral and no significant influence on TER after apical exposure for 12 and $24 \mathrm{~h}$. These findings may be due to an effect of absolute concentration of TNF- $\alpha$ per culture surface, which was $139 \mathrm{pg} /$ $0.33 \mathrm{~cm}^{2}$ for the apical side (NCI H441) and $732 \mathrm{pg} /$ $0.33 \mathrm{~cm}^{2}$ for the basolateral side (HPMEC). We are currently investigating different concentrations of TNF- $\alpha$. Another explanation of the average basolateral $30 \%$ reduction of TER-value compared to control (from $393 \pm 29$ to $267 \pm 8 \Omega \mathrm{cm}^{2}$ ) could be the breakdown of the endothelial barrier. Monocultures of NCI H441 exhibit maximum TER-values of $273 \pm 11 \Omega \mathrm{cm}^{2}$, which lie in the same range of TNF- $\alpha$ exposed cocultures. In addition, the minor changes in permeability, which is mainly influenced by the epithelial TJ, support this thesis. Furthermore, human bronchial epithelial cells also showed no difference in permeability in monocultures, which were basolateral exposed to TNF- $\alpha$ alone. ${ }^{77}$ The main effect of TNF- $\alpha$ on barrier disruption is described for endothelial cell monolayers, ${ }^{41-43,78}$ whereas for lung epithelial barrier disruption the costimulatory effect of additional cytokines is needed. ${ }^{77,79}$ The barrier function of the alveolar epithelium and endothelium may be regulated by costimulatory effects. Our reproducible coculture model will provide further insight into the interaction of these two essential cell types of a peripheral air-blood barrier. In future studies, we are planning to further define these interactions.

In conclusion, we have defined culture conditions for the in vitro coculture of human epithelial cell lines (A549, NCI H441), resembling ATII cell characteristics, and primary human lung microvascular endothelial cells. In contrast to A549, the cell line NCI H441 treated with Dex formed a tight and polarized cell layer when cocultivated with HPMEC on permeable filter supports. In a functional test, using TNF- $\alpha$ as a model cytokine, we induced an injured distal lung barrier with reduced TER-values, that could be re-established after removal of the cytokine. Our coculture system may therefore be a useful model for studies addressing the role of the differentiated endothelial and epithelial phenotype (cell polarity and tight barrier) in pathological 
processes, such as acute lung injury or lung toxicology. Experiments on the influence of cytokines, hypoxia and microbial toxins could be carried out to study the effects on barrier integrity and function. In addition, based on the formation of a functional barrier, the HTS 24-Transwell ${ }^{\circledR}$ coculture provides a suitable model system for the examination of lung drug delivery.

\section{Acknowledgements}

We thank Mrs A Stieglitz, L Meyer and M Müller for their excellent assistance with the cell culture, the immunocytochemical and TEM studies, respectively. This study was supported by the BMVg Grant E/B41G/1G302/1A402.

\section{References}

1 Balda MS, Matter K. Tight junctions. J Cell Sci 1998; 111:541-547.

2 Gehr P, Bachofen M, Weibel ER. The normal human lung: ultrastructure and morphometric estimation of diffusion capacity. Respir Physiol 1978;32: 121-140.

3 Matthay MA. Function of the alveolar epithelial barrier under pathologic conditions. Chest 1994;105(3 Suppl): $67 \mathrm{~S}-74 \mathrm{~S}$.

4 Inoue S, Michel RP, Hogg JC. Zonulae occludentes in alveolar epithelium and capillary endothelium of dog lungs studies with the freeze-fracture technique. J Ultrastruct Res 1976;56:215-225.

5 Schneeberger EE, Walters DV, Olver RE. Development of intercellular junctions in the pulmonary epithelium of the foetal lamb. J Cell Sci 1978;32:307-324.

6 Gorin AB, Stewart PA. Differential permeability of endothelial and epithelial barriers to albumin flux. J Appl Physiol 1979;47:1315-1324.

7 Crapo JD, Barry BE, Gehr P, et al. Cell number and cell characteristics of the normal human lung. Am Rev Respir Dis 1982;126:332-337.

8 Mason RJ, Lewis MC, Edeen KE, et al. Maintenance of surfactant protein A and D secretion by rat alveolar type II cells in vitro. Am J Physiol Lung Cell Mol Physiol 2002;282:L249-L258.

9 Nielsen S, King LS, Christensen BM, et al. Aquaporins in complex tissues. II. Subcellular distribution in respiratory and glandular tissues of rat. Am J Physiol Cell Physiol 1997;273:C1549-C1561.

10 Kreda SM, Gynn MC, Fenstermacher DA, et al. Expression and localization of epithelial aquaporins in the adult human lung. Am J Respir Cell Mol Biol 2001;24:224-234.

11 Dagenais A, Denis C, Vives M-F, et al. Modulation of \{alpha\}-ENaC and \{alpha\}1-Na+-K+-ATPase by cAMP and dexametha. Am J Physiol Lung Cell Mol Physiol 2001;281:L217-L230.

12 Verkman AS, Matthay MA, Song Y. Aquaporin water channels and lung physiology. Am J Physiol Lung Cell Mol Physiol 2000;278:L867-L879.

13 Adamson IY, Bowden DH. The type 2 cell as progenitor of alveolar epithelial regeneration. A cytodynamic study in mice after exposure to oxygen. Lab Invest 1974;30:35-42.
14 Uhal BD. Cell cycle kinetics in the alveolar epithelium. Am J Physiol Lung Cell Mol Physiol 1997;272: L1031-L1045.

15 Crouch EC. Collectins and pulmonary host defense. Am J Respir Cell Mol Biol 1998;19:177-201.

16 Rodriguez-Boulan E, Nelson WJ. Morphogenesis of the polarized epithelial cell phenotype. Science 1989;245: 718-725.

17 Fanning AS, Jameson BJ, Jesaitis LA, et al. The tight junction protein ZO-1 establishes a link between the transmembrane protein occludin and the actin cytoskeleton. J Biol Chem 1998;273:29745-29753.

18 Yonemura S, Itoh M, Nagafuchi A, et al. Cell-to-cell adherens junction formation and actin filament organization: similarities and differences between nonpolarized fibroblasts and polarized epithelial cells. J Cell Sci 1995;108:127-142.

19 Ando-Akatsuka Y, Yonemura S, Itoh M, et al. Differential behavior of E-cadherin and occludin in their colocalization with ZO-1 during the establishment of epithelial cell polarity. J Cell Physiol 1999;179: 115-125.

20 Suzuki A, Ishiyama C, Hashiba K, et al. aPKC kinase activity is required for the asymmetric differentiation of the premature junctional complex during epithelial cell polarization. J Cell Sci 2002;115:3565-3573.

21 Schnittler HJ. Structural and functional aspects of intercellular junctions in vascular endothelium. Basic Res Cardiol 1998;93:30-39.

22 Vestweber D. Molecular mechanisms that control endothelial cell contacts. J Pathol 2000;190:281-291.

23 Cereijido M, Shoshani L, Contreras RG. Molecular physiology and pathophysiology of tight junctions I. Biogenesis of tight junctions and epithelial polarity. Am J Physiol Gastrointest Liver Physiol 2000;279: G477-G482.

24 Lampugnani MG, Dejana E. Interendothelial junctions: structure, signalling and junctional roles. Curr Opin Cell Biol 1997;9:674-682.

25 Dejana E, Lampugnani MG, Martinez-Estrada O, et al. The molecular organization of endothelial junctions and their functional role in vascular morphogenesis and permeability. Int J Dev Biol 2000;44(6 Spec No):743-748.

26 Godfrey RW. Human airway epithelial tight junctions. Microsc Res Tech 1997;38:488-499.

27 Mason RJ, Williams MC. Phospholipid composition and ultrastructure of A549 cells and other cultured pulmonary epithelial cells of presumed type II cell origin. Biochim Biophys Acta 1980;617:36-50.

28 Masuda A, Kondo M, Saito T, et al. Establishment of human peripheral lung epithelial cell lines (HPL1) retaining differentiated characteristics and responsiveness to epidermal growth factor, hepatocyte growth factor, and transforming growth factor beta1. Cancer Res 1997;57:4898-4904.

29 Winton HL, Wan H, Cannell MB, et al. Cell lines of pulmonary and non-pulmonary origin as tools to study the effects of house dust mite proteinases on the regulation of epithelial permeability. Clin Exp Allergy 1998;28:1273-1285.

30 Zettl KS, Sjaastad MD, Riskin PM, et al. Glucocorticoid-induced formation of tight junctions in mouse mammary epithelial cells in vitro. PNAS 1992;89: 9069-9073.

31 Buse P, Woo PL, Alexander DB, et al. Glucocorticoidinduced functional polarity of growth factor responsiveness regulates tight junction dynamics in trans- 
formed mammary epithelial tumor cells. J Biol Chem 1995;270:28223-28227.

32 Antonetti DA, Wolpert EB, DeMaio L, et al. Hydrocortisone decreases retinal endothelial cell water and solute flux coincident with increased content and decreased phosphorylation of occludin. J Neurochem 2002;80:667-677.

33 Hoheisel D, Nitz T, Franke H, et al. Hydrocortisone reinforces the blood-brain properties in a serum free cell culture system. Biochem Biophys Res Commun 1998;247:312-315.

34 Beutler B, Bilsark IW, Cerami AC. Passive immunization against cachectin/tumor necrosis factor protects mice from lethal effect of endotoxin. Science 1985;229: 869-871.

35 Hyers TM, Tricomi SM, Dettenmeier PA, et al. Tumor necrosis factor levels in serum and bronchoalveolar lavage fluid of patients with the adult respiratory distress syndrome. Am Rev Respir Dis 1991;144:268-271.

36 Suter PM, Suter S, Girardin E, et al. High bronchoalveolar levels of tumor necrosis factor and its inhibitors, interleukin-1, interferon, and elastase, in patients with adult respiratory distress syndrome after trauma, shock, or sepsis. Am Rev Respir Dis 1992;145:1016-1022.

37 Jarrar D, Kuebler JF, Rue III LW, et al. Alveolar macrophage activation after trauma-hemorrhage and sepsis is dependent on NF-kappa B and MAPK/ERK mechanisms. Am J Physiol Lung Cell Mol Physiol 2002;283:L799-L805.

38 Johnson J, Meyrick B, Jesmok G, et al. Human recombinant tumor necrosis factor alpha infusion mimics endotoxemia in awake sheep. J Appl Physiol 1989;66:1448-1454.

39 Hocking D, Phillips P, Ferro T, et al. Mechanisms of pulmonary edema induced by tumor necrosis factoralpha. Circ Res 1990;67:68-77.

40 Serfilippi G, Ferro TJ, Johnson A. Activation of protein kinase $\mathrm{C}$ mediates altered pulmonary vasoreactivity induced by tumor necrosis factor-alpha. Am J Physiol Lung Cell Mol Physiol 1994;267:L282-L290.

41 Petrache I, Birukova A, Ramirez SI, et al. The role of the microtubules in tumor necrosis factor-\{alpha\}induced endothelial cell permeability. Am J Respir Cell Mol Biol 2003;28:574-581.

42 Nwariaku FE, Rothenbach P, Liu Z, et al. Rho inhibition decreases TNF-induced endothelial MAPK activation and monolayer permeability. J Appl Physiol 2003;95:1889-1895.

43 Goldblum SE, Ding X, Campbell-Washington J. TNFalpha induces endothelial cell F-actin depolymerization, new actin synthesis, and barrier dysfunction. Am J Physiol Cell Physiol 1993;264:C894-C905.

44 Wagner M, Hermanns I, Bittinger F, et al. Induction of stress proteins in human endothelial cells by heavy metal ions and heat shock. Am J Physiol Lung Cell Mol Physiol 1999;277:L1026-L1033.

45 Unger RE, Krump-Konvalinkova V, Peters K, et al. In vitro expression of the endothelial phenotype: comparative study of primary isolated cells and cell lines, including the novel cell line HPMEC-ST1.6R. Microvasc Res 2002;64:384-397.

46 Krump-Konvalinkova V, Bittinger F, Unger RE, et al. Generation of human pulmonary microvascular endothelial cell lines. Lab Invest 2001;81:1717-1727.

47 Geyer H, Geyer R, Odenthal-Schnittler M, et al. Characterisation of human vascular endothelial cadherin glycans. Glycobiology 1999;9:915-925.
48 Muller AM, Hermanns MI, Cronen C, et al. Comparative study of adhesion molecule expression in cultured human macro- and microvascular endothelial cells. Exp Mol Pathol 2002;73:171-180.

49 Planus E, Galiacy S, Matthay M, et al. Role of collagenase in mediating in vitro alveolar epithelial wound repair. J Cell Sci 1999;112:243-252.

50 Fehrenbach H. Alveolar epithelial type II cell: defender of the alveolus revisited. Respir Res 2001;2:33-46.

51 Kelly JJ, Moore TM, Babal P, et al. Pulmonary microvascular and macrovascular endothelial cells: differential regulation of $\mathrm{Ca}^{2+}$ and permeability. Am J Physiol Lung Cell Mol Physiol 1998;274:L810-L819.

52 Cunningham AC, Kirby JA. Regulation and function of adhesion molecule expression by human alveolar epithelial cells. Immunology 1995;86:279-286.

53 Rosseau S, Selhorst J, Wiechmann K, et al. Monocyte migration through the alveolar epithelial barrier: adhesion molecule mechanisms and impact of chemokines. J Immunol 2000;164:427-435.

54 Elbert KJ, Schafer UF, Schafers HJ, et al. Monolayers of human alveolar epithelial cells in primary culture for pulmonary absorption and transport studies. Pharm Res 1999;16:601-608.

55 Fuchs S, Hollins AJ, Laue M, et al. Differentiation of human alveolar epithelial cells in primary culture: morphological characterization and synthesis of caveolin-1 and surfactant protein-C. Cell Tissue Res 2003;311:31-45.

56 Lieber M, Smith B, Szakal A, et al. A continuous tumor-cell line from a human lung carcinoma with properties of type II alveolar epithelial cells. Int J Cancer 1976;17:62-70.

57 Hoshino Y, Mio T, Nagai S, et al. Cytotoxic effects of cigarette smoke extract on an alveolar type II cellderived cell line. Am J Physiol Lung Cell Mol Physiol 2001;281:L509-L516.

58 Dentener MA, Vreugdenhil ACE, Hoet PHM, et al. Production of the acute-phase protein lipopolysaccharide-binding protein by respiratory type II epithelial cells. Implications for local defense to bacterial endotoxins. Am J Respir Cell Mol Biol 2000;23: 146-153.

59 Hukkanen J, Lassila A, Paivarinta K, et al. Induction and regulation of xenobiotic-metabolizing cytochrome P450s in the human A549 lung adenocarcinoma cell line. Am J Respir Cell Mol Biol 2000;22:360-366.

60 Koyama S, Sato E, Masubuchi T, et al. Alveolar type IIlike cells release G-CSF as neutrophil chemotactic activity. Am J Physiol Lung Cell Mol Physiol 1998; 275:L687-L693.

61 Gazdar AF, Linnoila RI, Kurita Y, et al. Peripheral airway cell differentiation in human lung cancer cell lines. Cancer Res 1990;50:5481-5487.

62 Chess PR, Ryan RM, Finkelstein JN. H441 pulmonary epithelial cell mitogenic effects and signaling pathways in response to HGF and TGF-alpha. Exp Lung Res 1998;24:27-39.

63 Weaver TE, Na CL, Stahlman M. Biogenesis of lamellar bodies, lysosome-related organelles involved in storage and secretion of pulmonary surfactant. Semin Cell Dev Biol 2002;13:263-270.

64 Kim K-J, Malik AB. Protein transport across the lung epithelial barrier. Am J Physiol Lung Cell Mol Physiol 2003;284:L247-L259.

65 Foster KA, Oster CG, Mayer MM, et al. Characterization of the A549 cell line as a type II pulmonary 
epithelial cell model for drug metabolism. Exp Cell Res 1998;243:359-366.

66 Carolan EJ, Mower DA, Casale TB. Cytokine-induced neutrophil transepithelial migration is dependent upon epithelial orientation. Am J Respir Cell Mol Biol 1997;17:727-732.

67 Birkness KA, Deslauriers M, Bartlett JH, et al. An in vitro tissue culture bilayer model to examine early events in Mycobacterium tuberculosis infection. Infect Immun 1999;67:653-658.

68 Harvey BJ, Alzamora R, Healy V, et al. Rapid responses to steroid hormones: from frog skin to human colon. A homage to Hans Ussing. BBA-Biomembranes 2002; 1566:116-128.

69 Kassab Jr F, Marques RP, Lacaz-Vieira F. Modeling tight junction dynamics and oscillations. J Gen Physiol 2002;120:237-247.

70 Lacaz-Vieira F. Calcium site specificity. Early $\mathrm{Ca}^{2+}$-related tight junction events. J Gen Physiol 1997;110:727-740.

71 Kurzen H, Manns S, Dandekar G, et al. Tightening of endothelial cell contacts: a physiologic response to cocultures with smooth-muscle-like $10 \mathrm{~T} 1 / 2$ cells. J Invest Dermatol 2002;119:143-153.

72 Shannon JM, Pan T, Nielsen LD, et al. Lung fibroblasts improve differentiation of rat type II cells in primary culture. Am J Respir Cell Mol Biol 2001;24:235-682.
73 Bingle L, Bull T, Fox B, et al. Type II pneumocytes in mixed cell culture of human lung: a light and electron microscopic study. Environ Health Perspect 1990;85: 71-80.

74 Speirs V, Ray KP, Freshney RI. Paracrine control of differentiation in the alveolar carcinoma, A549, by human foetal lung fibroblasts. Br J Cancer 1991;64:693-699.

75 Underwood JL, Murphy CG, Chen J, et al. Glucocorticoids regulate transendothelial fluid flow resistance and formation of intercellular junctions. Am J Physiol Cell Physiol 1999;277:C330-C342.

76 Crandall ED, Matthay MA. Alveolar epithelial transport. Basic science to clinical medicine. Am J Respir Crit Care Med 2001;163:1021-1029.

77 Coyne CB, Vanhook MK, Gambling TM, et al. Regulation of airway tight junctions by proinflammatory cytokines. Mol Biol Cell 2002;13:3218-3234.

78 Blum MS, Toninelli E, Anderson JM, et al. Cytoskeletal rearrangement mediates human microvascular endothelial tight junction modulation by cytokines. Am J Physiol Heart Circ Physiol 1997;273:H286-H294.

79 Han X, Fink MP, Uchiyama T, et al. Increased iNOS activity is essential for the development of pulmonary epithelial tight junction dysfunction in endotoxemic mice. Am J Physiol Lung Cell Mol Physiol 2004;286: L259-L267. 